\title{
Effects of industrial processing on essential elements and regulated and emerging contaminant levels in seafood
}

Rasmussen, Rie Romme; Bøge Søndergaard, Annette; Bøknæs, Niels; Cederberg, Tommy Licht; Sloth, Jens Jørgen; Granby, Kit

Published in:

Food and Chemical Toxicology

Link to article, DOI:

10.1016/j.fct.2017.02.008

Publication date:

2017

Document Version

Peer reviewed version

Link back to DTU Orbit

Citation (APA):

Rasmussen, R. R., Bøge Søndergaard, A., Bøknæs, N., Cederberg, T. L., Sloth, J. J., \& Granby, K. (2017).

Effects of industrial processing on essential elements and regulated and emerging contaminant levels in seafood. Food and Chemical Toxicology, 104, 85-94. https://doi.org/10.1016/j.fct.2017.02.008

\section{General rights}

Copyright and moral rights for the publications made accessible in the public portal are retained by the authors and/or other copyright owners and it is a condition of accessing publications that users recognise and abide by the legal requirements associated with these rights.

- Users may download and print one copy of any publication from the public portal for the purpose of private study or research.

- You may not further distribute the material or use it for any profit-making activity or commercial gain

- You may freely distribute the URL identifying the publication in the public portal 
Effects of industrial processing on essential elements and regulated and emerging contaminant levels in seafood

\title{
Authors
}

Rie Romme Rasmussen ${ }^{a^{*}}$, Annette Bøge Søndergaard ${ }^{\mathrm{bc}}$, Niels Bøknæs ${ }^{\mathrm{bc}}$, Tommy Licht Cederberg ${ }^{\mathrm{a}}$, Jens Jørgen Sloth ${ }^{\text {a }}$, Kit Granby ${ }^{\mathrm{a}}$.

${ }^{a}$ Technical University of Denmark (DTU), National Food Institute, Anker Engelundsvej 1, DK-2800 Lyngby, Denmark

${ }^{b}$ DanSalmon A/S, Østhavnsvej 12, DK-9850 Hirtshals, Denmark

${ }^{\mathrm{c}}$ Royal Greenland A/S, Hellebarden 7, DK-9230 Svenstrup J, Denmark

${ }^{*}$ Corresponding author;

Rie Romme Rasmussen

Chemist, MSc, PhD

Technical University of Denmark, National Food Institute

Bygning 202, Anker Engelundsvej 1,

2800 Lyngby, Danmark

Direct phone +45 35887455, Email: riro@food.dtu.dk

\section{Highlights}

- Non-toxic organic arsenic was not transformed to carcinogenic inorganic arsenic by industrial smoking or cooking of seafood.

- Peeling prawns increased $\mathrm{Hg}$ but reduced the other elements including iAs, As, Cr, Zn, Se and especially $\mathrm{Cd}, \mathrm{Cu}$ and Fe.

- Cold smoking increased PCBs in Greenland halibut per wet weight, but levels were not changed based on lipid or dry matter.

\begin{abstract}
Mitigation of contaminants in industrial processing was studied for prawns (cooked and peeled), Greenland halibut (cold smoked) and Atlantic salmon (cold smoked and trimmed). Raw prawns had significantly higher cadmium, chromium, iron, selenium and zinc content in autumn than in spring, while summer levels typically were intermediate. Peeling raw prawns increased mercury concentration but reduced the concentration of all other elements including inorganic arsenic, total arsenic, chromium, zinc, selenium but especially cadmium, copper and iron $(p<0.05)$, however interaction between seasons and processing was observed.

Non-toxic organic arsenic in raw Greenland halibut $(\mathrm{N}=10)$ and salmon ( $\mathrm{N}=4)$ did not transform to carcinogenic inorganic arsenic during industrial cold smoking. Hence inorganic arsenic was low $(<0.003$ $\mathrm{mg} / \mathrm{kg}$ wet weight) in both raw and smoked fillets rich in organic arsenic (up to 9.0 for farmed salmon and $0.7 \mathrm{mg} / \mathrm{kg}$ wet weight for wild caught Greenland halibut). Processing salmon did not significantly change any levels (calculated both per wet weight, dry weight or lipid content). Cold smoking decreased total arsenic (17\%) and increased PCB congeners (10-22\%) in Greenland halibut (wet weight). However PFOS, PCB and PBDE congeners were not different in processed Greenland halibut when corrected for water loss or lipid content.
\end{abstract}

\section{Keywords}

season; toxic elements; halogenated organic contaminants; cold smoking; cooking; peeling

\section{Abbreviations}

$\alpha$-hexabromocyclododecane $(\alpha-H B C D)$

2,4,6-tribromophenol (2,4,6-TBP)

arsenic (As) bismuth (Bi)

brominated flame retardants (BFR)

cadmium (Cd) 
chromium $(\mathrm{Cr})$

cobber $(\mathrm{Cu})$

gas chromatography high-resolution mass

spectrometry (GC-HRMS)

indium (In)

inorganic arsenic (iAs)

iron $(\mathrm{Fe})$

lead $(\mathrm{Pb})$

liquid chromatography tandem mass spectrometry

(LC-MS/MS)

mercury $(\mathrm{Hg})$ perfluorinated compound (PFC)

perfluorononanoate (PFNA)

perfluorooctane sulfonamide (PFOSA)

perfluorooctane sulfonate (PFOS)

perfluorooctanoate (PFOA)

polybrominated diphenyl ether (PBDE)

polychlorinated biphenyls (PCB)

selenium (Se)

tetrabrombisphenol A (TBBPA)

tin $(S n)$

zinc $(\mathrm{Zn})$

\section{Introduction}

Seafood is one of the most important food commodities consumed worldwide and recognized as a highquality and healthy food item. Although marine fish supplies have been declining during recent years, farmed aquaculture products continue to increase globally (constituting around $50 \%$ of the total seafood market) due to the technological advances in production and relatively lower production costs (compared to non-farmed fisheries; FAO, 2014). Aquaculture has contributed to a rise in fish consumption in Europe that has now stabilised at $22 \mathrm{~kg}$ per capita per year, with Iceland and Portugal being the populations with the highest intake. Seafood is an important source of several beneficial components (e.g. $\omega 3$ polyunsaturated fatty acids (PUFAs), vitamin D, selenium and iodine) and the health benefits of a diet, which is rich in seafood have been extensively recognized. The World Health Organization (WHO), the Food and Agriculture Organization (FAO) as well as several national food authorities recommend a regular fish consumption of 1-2 servings per week in order to provide an adequate level of w3-PUFA (FAONHO, 2003). On the other hand, seafood, like other types of food, may also be a source of exposure for humans to environmental contaminants like persistent organic pollutants (POPs) and toxic elements. Currently, the contaminant level in seafood is in most countries being monitored by national surveillance programmes, which form the basis for conduction of risk assessment and risk management with regards to seafood consumption. However, at present, only relatively few data is available for contaminants where no maximum limits have been set by authorities, i.e. the so-called emerging contaminants (Vandermeersch et al 2015), which include compounds such as toxic elements, endocrine disruptors, brominated flame retardants, pharmaceuticals and personal care products, polycyclic aromatic hydrocarbons and derivatives, microplastics and marine toxins. The Marine Strategy Framework Directive emphasizes the need for further monitoring of these compounds in seafood for human consumption for determination of Good Environmental Status of the marine environment (MSFD, 2010). For non dioxin-like PCB maximum levels have been established by European Commission Regulation 1259/2011 (ECR, 2011).

Trace elements occur widely in all types of foodstuffs, either because of their natural occurrence in the environment or from contamination during food production, processing and storage. Essential trace elements (e.g. iron, zinc, copper, selenium, chromium and iodine) are crucial for human health whereas others are potentially dangerous (De la Guardia and Garrigues, 2015). Seafood has been identified as one of the food items which may contain relatively high concentrations of a number of the toxic trace elements (Llobet et al., 2003; Bocio et al., 2005), typically identified as lead, cadmium and mercury, for which maximum limit in seafood are regulated by the European Commission regulation1881/2006 (ECR, 2006). For other (toxic) trace elements, so far no maximum levels have been laid down in the EU legislation, partly due to lack of knowledge on their occurrence in seafood. For some trace elements, the chemical form (i.e. the elemental speciation) in which the element is ingested may play a significant role from a toxicological point of view. For example, methylmercury is known to be much more toxic than inorganic mercury compounds, while inorganic arsenic is known to be more toxic than the organic species of arsenic (EFSA, 2009, 2012).

Halogenated contaminants i.e. chlorinated contaminants such as polychlorinated biphenyls (PCBs), brominated flame retardants (BFR) as e.g. polybrominated diphenyl ethers (PBDEs) and hexabromocyclododecanes (HBCDs) and polyfluorinated compunds (PFC), are all anthropogenic persistent 
chemicals ubiquitous in the environment, even in remote places like the Arctic (Glasius et al., 2005). The chlorinated and brominated compounds are lipophilic and bioaccumulate and biomagnify in the lipid phases of the food chain, while the perfluorinated compounds have surfactant properties and more tend to occur in muscles tissue, liver and blood (Stahl. et al., 2011). The applications of brominated flame retardants are or have been as flame retardants in many materials including also plastics and the perfluorinated compounds are typically used in industrial and consumer products (impregnating agent for paper, textiles etc.) (Stahl et al., 2011). While PCB is a well-known contaminant, the occurrence of the other compound groups mentioned is not very frequently reported. Recent reports by e.g. Van Leeuwen et al. (2009) on halogenated contaminants in farmed seafood and Glasius et al $(2005)$ and Carlsson et al $(2014,2016)$ who conducted surveys of halogenated contaminants in seafood from remote areas of Greenland and Northern Norway, respectively, emphasise the increasing interest in these types of compounds.

The majority of data on contaminant level in seafood have been achieved from the analysis of raw seafood. However, most seafood is consumed processed and prepared and hence risk evaluations based on raw seafood may be biased when not taking the effect of processing on the contaminant level into account. Therefore, in order to conduct improved risk assessments, seafood processing and preparation procedures should also be taken into account. There is currently a lack in our knowledge on how industrial processing may influence the levels of contaminants in seafood. In order to improve the risk assessment further information on processed seafood is needed, so that the evaluation can be done on products being consumed.

The aim of the present study was to assess whether selected industrial processing procedures (smoking, fat trimming, peeling, cooking) affect the content of a range of emerging contaminants in seafood products. The results obtained in the study furthermore contribute with novel data on emerging contaminants in some commercially relevant seafood products, that is Atlantic salmon, Greenland halibut and prawns. In addition the seasonal influence on contamination levels in raw prawns and further processing mitigation was evaluated. It is expected that the results obtained here will be of value for future risk assessments of these contaminants in seafood and contribute to the optimization of industrial processing of seafood and hereby contribute to improving the food safety of these products.

\section{Materials and Methods}

\subsection{Prawns (Pandalus borealis)}

Prawns (3-7 years old) were caught by net near the west coast of Greenland (Figure 1) in the FAO 21 Major fishing area, more precise in the Northwest Atlantic Fisheries Organization (NAFO) subarea $1 A$ and 1B (grid LE23, LH25, LH24, LK25, LL25,LS14, LJ27, LT15, KG16, KR17 and KT17 in Figure S1). They were caught in different seasons; spring (25.3-1.4 2014), summer (15.-17.8 2014) and autumn (28.-29.11 2014). Each shipping of raw prawns was industrially processed at the Royal Greenland A/S factory in Sisimiut and Ilulisat into cooked prawns with shell/head/guts and cooked and peeled prawns without shell/head/guts. Raw and cooked prawns were sampled immediately before the cooker (CoolSteamCooker, Laitram Machinery, New Orleans, Lousiana, USA), peeled prawns were taken after the digester (Laitram Machinery) before glazing. Surface water from the city lake was applied in the processing. Samples within the season came from different areas and inshore vessels, but from the same maturation tank. Prawns $(500 \mathrm{~g})$ were packed in freezer bags, and pressed flat without air before freezing and were shipped $\left(-18^{\circ} \mathrm{C}\right)$ to Technical University of Denmark (DTU) for homogenization and trace element analysis (2015). Samples were milled when partly defrosted using a Robot-coupe Blixer 6 v.v. 1300 W, Vincennes Cedex, France) to achieve the most homogenous sample.

\subsection{Greenland halibut (Reinhardtius hippoglossoides)}

The Greenland halibut $(n=10)$ was caught (26.01.2014) by long line near llulissat, West Greenland (Figure 1) in FAO 21, NAFO 1A (grid LG28, LH28, LG30 in Figure S1). The Greenland halibuts (size: $3.5-5 \mathrm{~kg}$, corresponding to 10-13 years) were filleted and frozen (at Qasigiannguit, Greenland) three days after 
catching and arrived (February 2014) to DanSalmon A/S (Hirtshals, Denmark) in blocks of $20 \mathrm{~kg}$. DanSalmon marked the fillets to make sure that they came from the same block and processed one of them by cold smoking. The process step for cold smoking at DanSalmon consisted in: a) thawing at $2{ }^{\circ} \mathrm{C}$; b) salt and lactic acid is added by injection; c) cold storage for equalization during 7 hours at max. $5^{\circ} \mathrm{C}$; d) drying: $5 \frac{1}{2}$ hour and e) smoking: 4 hours. Drying and smoking is done at $23-25{ }^{\circ} \mathrm{C}$. After drying and smoking the fillets were quickly frozen to $-11^{\circ} \mathrm{C}$. Pairs of raw and the corresponding processed loin fillets $(5-10 \mathrm{~cm}$ ) were sent to DTU (April 2014) for homogenization and analyses (2015/2016). Fish without skin were homogenised in a mini chopper (Philips, $700 \mathrm{~W}$ ) when partly defrosted.

\subsection{Atlantic salmon, farmed (Salmo Salar)}

The Atlantic salmons were farmed near Rørvig in Norway (Figure 1) by Sinkaberg Hansen A/S (approval no NT- 145 Marøy, 7900 Rørvik) and bought as a standard commercial product from Halvard Lerøy A/S. The fish (4-5 kg fresh weight) were slaughtered (25.11.2014), shipped $\left(0^{\circ}-2^{\circ} \mathrm{C}\right)$ to DanSalmon $\mathrm{A} / \mathrm{S}$ and smoked. The process step for cold smoked Atlantic salmon: Filleting by machinery, trimming by hand. Salt and lactic acid is adding by injection and dry salting. Equalization: 4 hours at max. $5^{\circ} \mathrm{C}$. Drying: 5 hours, smoking $3 \frac{1}{2}$ hour, drying and smoking are performed at $23^{\circ}-26^{\circ} \mathrm{C}$. The salmon is chilled after smoking to a core temperature of $0^{\circ} \mathrm{C}$. The Atlantic salmon was received by DTU $(27.11 .2014)$ and stored frozen $\left(-20^{\circ} \mathrm{C}\right)$. The skin was removed from the raw salmon but for smoked salmon both the skin and the fat below the skin was removed before the middle $10 \mathrm{~cm}$ of the fish fillet homogenised similar to the Greenland halibut (May 2015) and analysed for contaminants (2015).

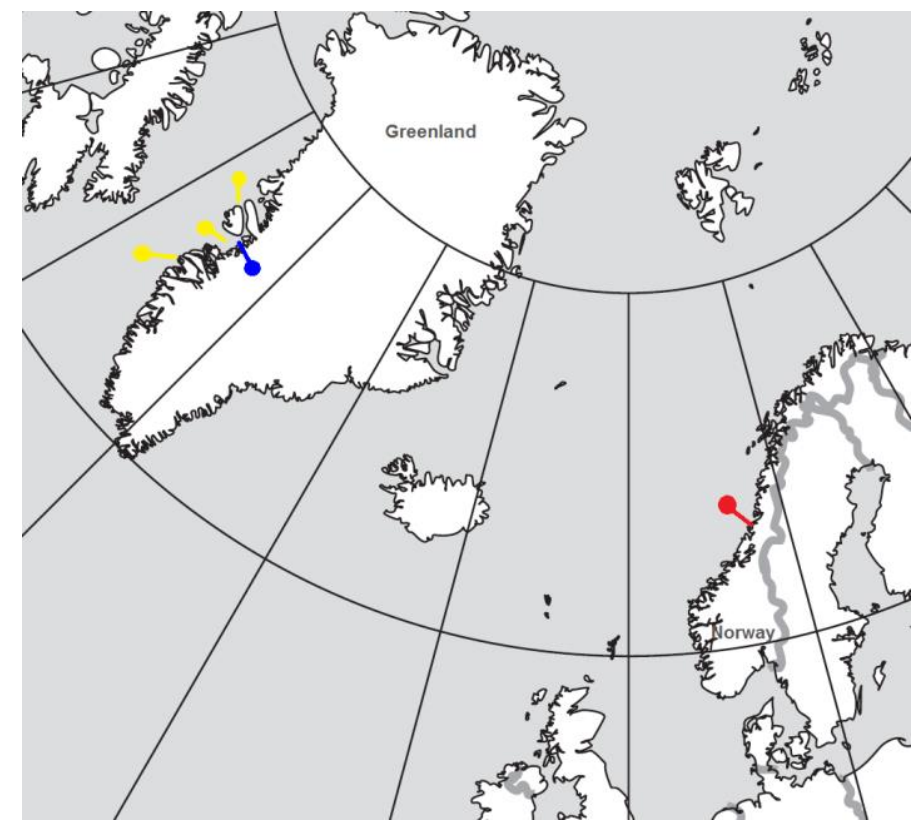

Figure 1. Fishing area for Atlantic salmon (Rørvik in Norway, red pin), Greenland halibut (llulissat in Greenland, blue pin) and prawns (Sisimut and several places round the Disco island, yellow pins). Map from Education place (2016) with modifications.

\subsection{Dry matter and lipid content}

Fish dry matter was determined by drying the samples to constant weight at $70^{\circ} \mathrm{C} \pm 2^{\circ} \mathrm{C}$ in a vacuum oven kept at $<50 \mathrm{~mm} \mathrm{Hg}$ according to a standard from Nordic Committee on Food Analysis (NMKL, 2002). The lipid content was measured from one fourth subsamples after soxhlet extraction of $4 \mathrm{~g}$ sample, ground with $60 \mathrm{~g}$ anhydrous sodium sulphate; with $150 \mathrm{~mL}$ acetone:hexane (1:1) for six hours. After gentle vacuum evaporation of the solvent, the samples were kept at $70{ }^{\circ} \mathrm{C}$ for two hours; reconditioned in an exicator for $10 \mathrm{~min}$. and then weighed until constant weight. All lipid contents were measured in duplicates.

\subsection{BFR, PFC and PCB}

The brominated flame retardants (BFRs) $\alpha$-hexabromoocyclododecane ( $\alpha$-HBCD), $\beta$-HBCD, $\gamma$-HBCD, 2,4,6-tribromphenol (2,4,6-TBP) and tetrabromobisphenol A (TBBPA) were determined both in Greenland 
halibut and Atlantic salmon by liquid chromatography tandem mass spectrometry (LC-MS/MS). The perfluorinated compounds (PFCs), including perfluorooctane sulfonate (PFOS), perfluorooctanoate (PFOA), perfluorononanoate (PFNA), perfluorooctane sulfonamide (PFOSA) were determined in Greenland halibut also by LC-MS/MS. The polybrominated diphenyl ether (PBDE) congeners (PBDE 47, PBDE 99, PBDE 154, PBDE 153) and polychlorinated biphenyls (PCB) congeners (PCB 28, PCB 52, PCB 101, PCB 153, PCB 138, PCB 180) were determined in Greenland halibut by gas chromatography high-resolution mass spectrometry (GC-HRMS). For method details see supplementary material "1.2 Chemical analysis".

The LC-MS/MS method for BFRs is validated (unpublished report) and accredited by the Danish accreditation body DANAK. a-HBCD merits from the validation include high accuracy and precision for spiked Atlantic salmon ( $\mathrm{n}=27) ; 97 \%$ recovery and $15 \%$ repeatability at $1 \mathrm{ng} / \mathrm{g} \mathrm{ww}$ and $91 \%$ recovery and $16 \%$ repeatability at $0.33 \mathrm{ng} / \mathrm{g}$ ww. The LOD of 2,4,6-TBP was $0.28 \mathrm{ng} / \mathrm{g}$ ww while the others were detectable above $0.05 \mathrm{ng} / \mathrm{g}$ ww. Also intercomparison results of $\mathrm{a}-\mathrm{HBCD}$ were in agreement with the UNEP global interlaboratory assessment of persistent organic pollutants, $3^{\text {rd }}$ round 2016 (UNEP 2017). The method for PFCs is validated (unpublished report) and accredited by the Danish accreditation body DANAK. The LODs were all low; PFOS (0.4 ng/g ww), PFOA (0.5 ng/g ww), PFNA (0.5 ng/g ww) and PFOSA (0.5 ng/g ww). High accuracy and precision for PFOS was obtained $(91 \%$ recovery and $14 \%$ repeatability) at a spike level of $1.7 \mathrm{ng} / \mathrm{g} w \mathrm{w}(\mathrm{n}=23)$. Furthermore satisfactory results, within the range of acceptance for the PFCs including PFOS were determined by our laboratory in an EU intercomparison on determination of PFASs in fish (Dehouck et al., 2015). For GC-HRMS the LOD based on signal to noise level of three in the mass fragmentograms was $0.005 \mathrm{ng} / \mathrm{g}$ wet weight (ww) for PCB and PBDE congeners, except for PBDE47 where it was $0.01 \mathrm{ng} / \mathrm{g}$ ww.

\subsection{Total elements, inorganic arsenic}

Total elements including arsenic (As), cadmium (Cd), chromium $(\mathrm{Cr})$, cobber $(\mathrm{Cu})$, iron $(\mathrm{Fe})$, lead $(\mathrm{Pb})$, mercury $(\mathrm{Hg})$, selenium $(\mathrm{Se})$, tin $(\mathrm{Sn})$ and zinc $(\mathrm{Zn})$ were determined by inductively coupled plasma mass spectrometer (ICP-MS). Inorganic arsenic (iAs) by anion exchange HPLC (High Performance Liquid Chromatography) coupled on-line to the ICP-MS. Determination of inorganic arsenic (iAs) followed the standard (EN 16802:2016) issued by European Committee for Standardization (CEN, 2016) and hydrogen peroxide ensured a quantitative oxidation of arsenite (iAs ${ }^{\mathrm{III}}$ ) to arsenate (iAs ${ }^{\mathrm{V}}$ ) (Rasmussen et al, 2012). For method details see supplementary material "1.2 Chemical analysis".

For total elements the limit of detection (LOD) was assigned to the detection limit (DL) of the calibration curve ( $D L=3 \times$ standard deviation $(\sigma)$ of response at the zero concentration level) and the limit of quantification (LOQ) was calculated as ( $3 \times L O D)$. The LOD and LOQ with all quality control results for the current analysis are presented in Table S2 (prawns) and Table S3 (fish) in the supplementary material. Overall satisfying results were achieved in both prawn and fish analyses. Accuracy and precision was evaluated by the certified reference material (CRM) "DORM-4" (Dogfish muscle) from National Research Council of Canada (Ontario, Canada). DORM-4 recoveries were between $86-111 \%$ for prawns and $85-$ $123 \%$ for fish analysis with less than $25 \%$ relative standard deviation (RSD) for all elements except for Sn. The recovery ranges were fine when both certificate range and analysis repeatability was taken into account. However Sn had too high DORM-4 recoveries (133\% and $173 \%$ ) maybe because Sn only was calibrated only at one level. However $\mathrm{Cr}$ levels 5-18 times the LOQ in fish were associated with too high RSD (65-82\%), which shows that the LOQ based on the calibration curve was too low. Instead a LOQ of $0.048 \mathrm{mg} / \mathrm{kg}$ for $\mathrm{Cr}$ is estimated based on the duplicate prawn samples. $\mathrm{Pb}$ cannot be determined at $\mathrm{LOQ}$ levels in the DTU Food lab due to diffuse contamination. But higher $\mathrm{Pb}$ concentrations are also biased (prawn $0.013 \mathrm{mg} / \mathrm{kg}$, RSD 102\% and smoked Atlantic salmon $0.0074 \mathrm{mg} / \mathrm{kg}$, RSD 145\%) with high variability. Therefore $\mathrm{Pb}$ is only reported as below the levels determined in the samples.

For inorganic arsenic LOD was assigned to $3 \times$ standard deviation $(\sigma)$ of response a blank sample $(n=4$ injections) and the limit of quantification (LOQ) was calculated as $10 \times \sigma$ according to IUPAC guidelines (Long and Winefordner, 1983). The iAs accuracy was evaluated by DORM-4 (Dogfish muscle) from National Research Council of Canada (Ontario, Canada) and ERM-BC211 (rice) from Institute of Reference 
Materials and Measurements, (Geel, Belgium) for elements. ERM-BC211 is certified for inorganic arsenic $(0.124+/-0.011 \mathrm{mg} / \mathrm{kg})$. DORM-4 is only certified for total metal but not for inorganic arsenic however a target value for iAs has recently been established in a collaborative trial at $0.270+/-0.040 \mathrm{mg} / \mathrm{kg}$ (mean+/standard deviation, $\mathrm{N}=13$ ) (Sloth, 2015). In the current analyses recoveries were satisfactory (88-117\%) and LOQ $0.0013 \mathrm{mg} / \mathrm{kg}$ ww in fish and prawn (Supplementary Table S1).

\subsection{Statistics}

Boxplot and paired t-test (raw versus smoked for Atlantic salmon and Greenland halibut respectively and raw versus peeled prawns) were produced in $\mathrm{R}$ studio ( $\mathrm{R}$ Core Team, 2015). This default boxplot shows median (solid line), first and third quartile and (box), 95\% confidence interval of median (whiskers) and outliers. Atlantic salmon and Greenland halibut data were fitted with a general linear model (GLM) with two main factors "fish" and "processing" and their interactions (y fish*processing) in Minitab (version 17, Statistical Software from Minitab Inc.). Significant differences were identified by Tukey's post-hoc test $(p<0.05)$.

Each shipload of prawns was sampled as raw, cooked and processed. The structure of sampling for prawns was included in the statistical analysis by adding "catch" as a random factor (Supplementary Table S9Table S9, pair = catching number). The linear mixed effects model $(y \sim$ season*processing $+(1 \mid$ catch $))$ was fitted with the Imer function from Ime4 package (Bates et al., 2015). The tests for the fixed effects used the ImerTest package (Kuznetsova et al., 2016). Multiple comparison tests were done with the Ismeans package (Russell, 2016). Stepwise reduction of the model was carried out for insignificant factors.

\section{Results and discussion}

Data were presented graphically as boxplots for regulated and emerging contaminants detected in Atlantic salmon, Greenland halibut and prawns (Figure 2, Figure 3 and Figure 4). Significantly different results were highlighted with different letters, numbers or asterisk. Find raw data (Table S4, Table S5, Table S6 and Table S9) and calculation of individual processing pairs (Table S7, Table S8 and Table S10) in supplementary.

\subsection{Atlantic salmon and Greenland halibut}

\subsubsection{Dry matter and lipid content}

Dry matter and lipid contents of Atlantic salmon were significantly higher than Greenland halibut per wet weight (ww) (Figure 2). Dry matter (49 \pm 5$)$ and lipid content $(20 \pm 2)$ in Atlantic salmon $(n=4)$ were unchanged after smoking and trimming, here reported as mean \pm standard derivation (sd) in \% ww. Raw Atlantic salmon fillets cold smoked by Birkeland et al. (2004) had slightly lower dry matter (36-42\%) and lipid content (16-21\%) than we observed. Contrary to the results obtained in this study an increase in fillet weight by $4 \%$ in cold smoked salmon was obtained, which was attributed to the relatively large amounts of salt solution applied. Injection of salt solution which adds water to the fillets is counteracted by water loss in the drying and smoking steps but also the fat trimming changes dry matter and lipid content. In the present study similar amounts of brine were injected into the fillets but Greenland halibut were dried and smoked 1 hour longer than the Atlantic salmon, the latter was also afterwards fat trimmed. The dry matter and lipid content of Atlantic salmon were not significantly different after processing while smoking of Greenland halibut $(n=10)$ significantly increased dry matter (30 \pm 1 to $36 \pm 2)$ and lipid contents $(14 \pm 1$ to $16 \pm 1)$ (mean \pm sd in \% ww). However when corrected for water loss the lipid contents of raw and smoked Greenland halibut were similar (45\%) per dry weight (dw). Julshamn et al. (2011) and Karl and Ruoff (2008) observed slightly lower dry matter (23\%) and lipid content (12\%) compared to our raw Greenland halibuts (ww). Correction for dry matter or lipid content is important to evaluate if the absolute contaminant level has changed. 
Drymatter (\%)

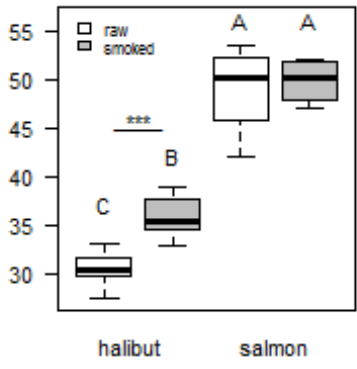

Zn

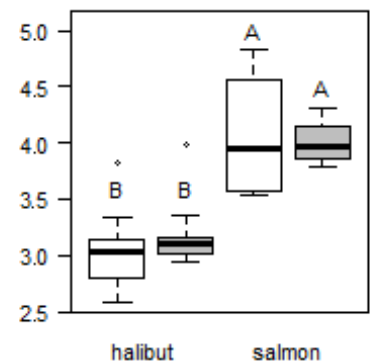

$\mathrm{Hg}$

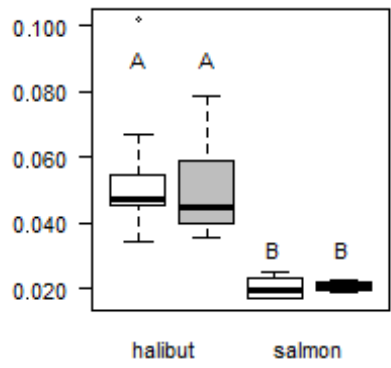

Lipid (\%)

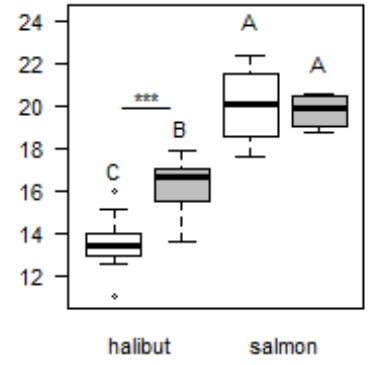

As

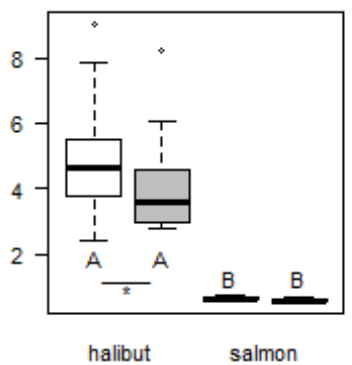

alfa-HBCD

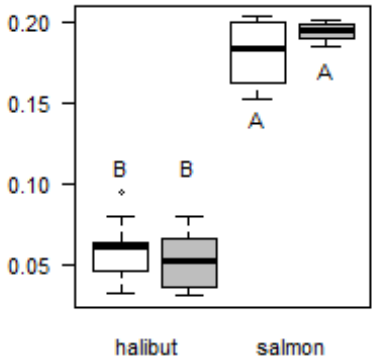

$\mathrm{Fe}$

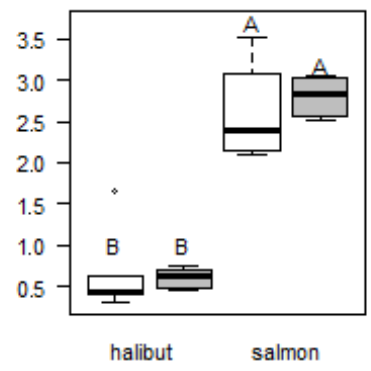

Se

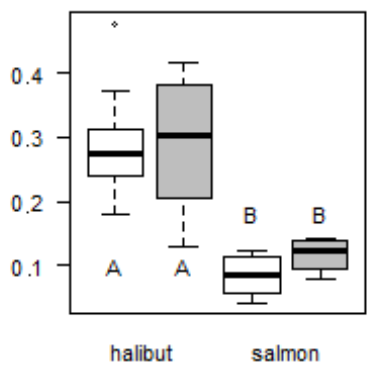

PFOS

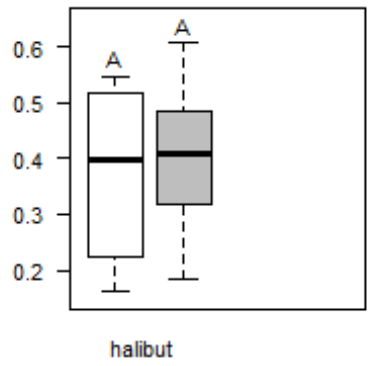

$\mathrm{Cu}$

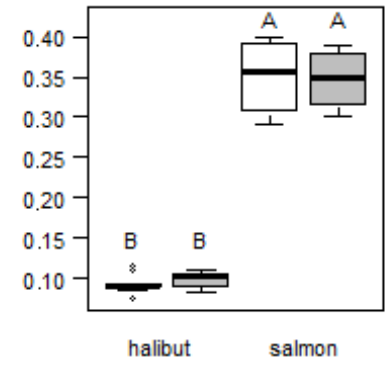

Cd

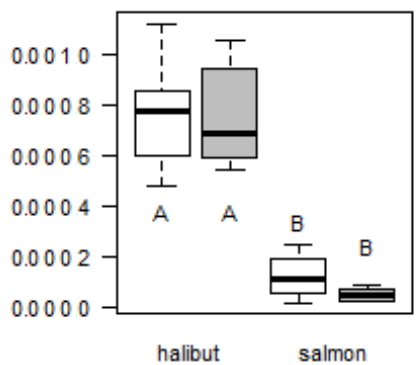

Figure 2. Dry matter (\%), lipid (\%), elements ( $\mathrm{mg} / \mathrm{kg}$ wet weight) and organic contaminants (ng/g wet weight) level in Greenland halibut $(n=10)$ and Atlantic salmon $(n=4)$. Displayed as a boxplot for raw (white) and smoked (grey) samples processed as paired fish fillets. Differences between raw and smoked fish were identified by paired t-test $\left({ }^{*}=p<0.05,{ }^{* * *}=p<0.001\right)$. A general linear model (GLM) with two main factors "fish" and "processing" and their interactions was performed. Different letters represent significant differences identified by Tukey's post-hoc test $(p<0.05)$.

\subsubsection{Elements}

Element compositions ( $\mathrm{Fe}, \mathrm{Cu}, \mathrm{Zn}, \mathrm{As}, \mathrm{Se}, \mathrm{Cd}, \mathrm{Hg}$ ) of Atlantic salmon and Greenland halibut (ww) were significantly different. Sn and iAs fish levels were below the LOQs ( $\mathrm{Sn}<0.0027$ and iAs $<0.0013 \mathrm{mg} / \mathrm{kg} \mathrm{ww}$ ) except for one smoked Greenland halibut $(\mathrm{Sn}=0.0029 \mathrm{mg} / \mathrm{kg} \mathrm{ww}$ ) and one raw Atlantic salmon (iAs = $0.0021 \mathrm{mg} / \mathrm{kg} \mathrm{ww}$ ). Pb levels were low in all samples; below $0.048 \mathrm{mg} / \mathrm{kg}$ ww for Greenland halibut and $0.008 \mathrm{mg} / \mathrm{kg} \mathrm{ww}$ for Atlantic salmon.

For raw Greenland halibut the element concentration were as follows in $\mathrm{mg} / \mathrm{kg}$ ww (mean $\pm \mathrm{sd}$ ( $\mathrm{min}$-max range)): Fe $0.57 \pm 0.40$ (0.31-1.67), Cu 0.09 \pm 0.01 (0.08-0.11), Zn 3.05 \pm 0.35 (2.59-3.82), As 5.05 \pm 2.06 (2.439.04), Se $0.29 \pm 0.08(0.18-0.48)$, Cd 0.00075 \pm 0.00019 (0.00048-0.0011) and $\mathrm{Hg} 0.054 \pm 0.019$ (0.0340.102). Riget et al. (2003) and Dietz et al. (1996) found similar low levels in Greenland halibut caught in West Greenland waters (mg/kg ww) for $\mathrm{Cd}(<0.002,<0.015$, respectively) and $\mathrm{Pb}(<0.010)$, similar Se $(0.31 \pm 0.12$, mean $\pm s d)$ but 3 times higher $\mathrm{Hg}(0.15 \pm 0.13$, mean \pm sd) levels compared to the present study. 
Two Greenland halibut caught north and northwest of Iceland had similar levels $(\mathrm{mg} / \mathrm{kg} \mathrm{ww})$ of Fe $(0.99$, 2.84), $\mathrm{Zn}(2.80,3.12)$, As $(2.62,10.09), \mathrm{Pb}(0.005,0.005)$ and slightly higher $\mathrm{Cu}(0.13,0.13)$, Se $(0.40$, 0.64), $\mathrm{Cd}(0.001,0.002$,$) and \mathrm{Hg}(0.085,0.336)$ levels (Ásmundsdóttir et al 2008). Greenland halibut caught in northern Norway (Julshamn et al., 2011, Julshamn et al., 2012) also had higher levels (mean \pm sd in $\mathrm{mg} / \mathrm{kg} \mathrm{ww})$ for $\mathrm{Hg}(0.23 \pm 0.22)$ and As $(8.1 \pm 6.2)$ but similar low iAs $(<0.004), \mathrm{Pb}(<0.001-0.011)$ and $\mathrm{Cd}$ $(<0.005-0.015)$ levels compared to the present study. Greenland halibut is a long-lived bottom-feeding predator fish and $\mathrm{Hg}$ was positively correlated not only to age, weight and length of the Greenland halibut but also to the geographical origin with shallow waters having highest concentrations (Julshamn et al., 2011). The relative low $\mathrm{Hg}$ levels reported in this study can presumably be attributed mainly to location differences, since the Greenland halibuts in the present study had similar weight $(3.5-5 \mathrm{~kg})$ as the ones investigated in the Julshamn et al. (2011) study (3.7 \pm 1.3 , mean $\pm \mathrm{sd}$ in $\mathrm{kg})$.

For raw Atlantic salmon the element concentrations were as follows (mean $\pm \mathrm{sd}$ (min - max range)) in $\mathrm{mg} / \mathrm{kg}$ ww: Fe 2.61 \pm 0.65 (2.10-3.52), Cu $0.35 \pm 0.05$ (0.29-0.40), Zn 4.06 \pm 0.61 (3.53-4.83), As $0.65 \pm 0.07$ (0.59$0.74)$, Se $0.084 \pm 0.035$ (0.042-0.122), Cd 0.00012 \pm 0.00010 (0.00002-0.00025) and Hg 0.020 \pm 0.004 (0.0170.0254). Similar concentrations were reported for $\mathrm{As}, \mathrm{Cd}, \mathrm{Pb}$ and $\mathrm{Hg}$ in a large-scale monitoring study of Norwegian farmed Atlantic salmon ( $\mathrm{N}=1025$, time period 2005-2011) (Nøstbakken, 2015).

The European maximum levels $(\mathrm{ML})$ for $\mathrm{Cd}(0.050 \mathrm{mg} / \mathrm{kg}), \mathrm{Hg}(0.50 \mathrm{mg} / \mathrm{kg})$ and $\mathrm{Pb}(0.30 \mathrm{mg} / \mathrm{kg})$ in wet weight muscle meat were not exceeded in neither raw nor processed fish (ECR, 2006).

The concentration of iAs was low $(<0.003 \mathrm{mg} / \mathrm{kg} \mathrm{ww})$ in both raw and smoked Atlantic salmon and Greenland halibut, indicating that organic As compounds were not transformed into inorganic arsenic during the industrial smoking process. Most of the element levels (ww) were not significantly changed by cold smoking of the fish, except for As, which decreased by $17 \%$ in smoked Greenland halibut (ww). Corrected for dry matter or lipid contents both total As, Zn and Hg levels significantly decreased in smoked Greenland halibut. The reason for reductions of some elements (As, Zn, Hg) and not others (Fe, $\mathrm{Cu}, \mathrm{Se}$, Cd) after cold smoking of Greenland halibut is not clear. Injection of salt solution (free of As, $\mathrm{Zn}$ and $\mathrm{Hg}$ ), drip loss of fat (rich in arsenolipids) or water loss (containing only selected elements) are possible but not obvious explanations. The difference between Atlantic salmon and Greenland halibut should not only be attributed to their different initial level of element and different industrial processing but also to the fact that less observations for Atlantic salmon was included and larger differences or mores samples were needed to observe significant differences.

\subsubsection{Perfluorinated compounds}

Perfluorinated compounds were only analysed in Greenland halibut and only PFOS was detectable in fillets with mean contents in both raw and smoked Greenland halibut of $0.4 \mathrm{ng} / \mathrm{g} \mathrm{ww}(0.2-0.6 \mathrm{ng} / \mathrm{g} \mathrm{ww}$,), i.e. around the LOD of $0.4 \mathrm{ng} / \mathrm{g}$ ww (plotted in Figure 2), while PFOA $(<0.4 \mathrm{ng} / \mathrm{g} \mathrm{ww})$, PFNA $(<0.4 \mathrm{ng} / \mathrm{g} w w)$ and PFOSA $(<0.6 \mathrm{ng} / \mathrm{g} \mathrm{ww})$ were below LOD. In a study of polyfluorinated compounds in halibut caught from coastal waters close to Tromsø, Northern Norway in 2012, Carlsson et al (2016) found PFOS at 0.2-1.7 $\mathrm{ng} / \mathrm{g}$ ww $(\mathrm{n}=9)$. They found that contrary to the lipid soluble contaminants, the content of the more polar PFOS was inversely related to the halibut mass. In another study of perfluorinated compounds in smoked halibut fillet from Greenland, they found very few contents above LOD $(0.2 \mathrm{ng} / \mathrm{g} \mathrm{ww})$, however the highest occurrence in other biota was of PFOS (Carlsson et al 2014).

\subsubsection{Brominated flame retardants (BFR) and PCB}

Of the BFRs analysed by LC-MS/MS only $\alpha-H B C D$ was quantitatively determined in Atlantic salmon and Greenland halibut while the others were below the LOD; $\beta$-HBCD, $\gamma$-HBCD, TBBPA (all $<0.05 \mathrm{ng} / \mathrm{g} w w$ ) or near the LOD; 2,4,6-TBP $(<0.28 \mathrm{ng} / \mathrm{g} w \mathrm{w})$. The contents of $\alpha-\mathrm{HBCD}$ in raw and smoked fillets from ten individual Greenland halibuts are presented in Figure 2. The concentrations are very low, some around LOD; however we performed double determinations and present all data for comparison including pooled relative standard derivations (Table S5). The mean $\alpha-H B C D$ content of the processed Greenland halibut fillets is at the same level $(\sim 0.05 \mathrm{ng} / \mathrm{g} \mathrm{ww})$ compared to the raw fillet contents $(\sim 0.06 \mathrm{ng} / \mathrm{g} \mathrm{ww})$. The $\alpha$ - 
HBCD contents of farmed Atlantic salmon are roughly four times higher with mean contents of $0.18 \mathrm{ng} / \mathrm{g}$ ww and $0.20 \mathrm{ng} / \mathrm{g} w \mathrm{w}$ for the raw and smoked fillets respectively, i.e. insignificant difference $(\mathrm{p}>0.05)$. The $\alpha-H B C D$ concentrations of Atlantic salmon occur as a result of carryover from the feed. As the fat contents of especially raw Atlantic salmon fillets vary it is not possible to see a reduction from fat trimming and smoking of fillets. The trimmed fat had not significantly different concentrations of $\alpha-H B C D$ on a lipid basis as the raw and the smoked fillets (Table S6). Van Leeuwen et al (2009) did not find $\alpha$-HBCD in farmed Atlantic salmon from Chile (LOD $0.1 \mathrm{ng} / \mathrm{g} \mathrm{ww}$ ), probably because the persistent environmental pollutants are lower in the Southern Hemisphere. However they found a mean content in all the worldwide farmed Atlantic salmon $\sim 0.2 \mathrm{ng} / \mathrm{g}$ ww as in the present study. HBCD is ubiquitous in the Arctic, it undergoes long range atmospheric transport and the $\alpha$-isomer biomagnifies (Wit et al 2010). The levels found in Greenland halibut in the present study ( $0.4 \mathrm{ng} / \mathrm{g}$ lipid) are comparable to what has been found in fish from the Arctic i.e. $\sim 0.4-1.2 \mathrm{ng} / \mathrm{g}$ lipid weight (Wit et al 2010).

PCB and PBDE congeners were determined in Greenland halibut raw fillet and the corresponding dried and cold smoked fillet. The obtained results from ten individual Greenland halibuts are shown in Figure 3 as boxplot for raw and smoked samples. Six PCB congeners (PCB 28, 52, 101, 138, 153 and 180) and four PBDE congeners (PBDE 47, 99, 153 and 154) were measured. The overall pattern of the congeners within the individual Greenland halibut is consistent. For PCB the content of PCB 153 was the largest followed by PCB 28, 101, and 138 at slightly lower levels and then PCB 52 and PCB 180. The content of PCB 153 ranged from 0.75 to $1.38 \mathrm{ng} / \mathrm{g}$ ww and $\mathrm{PCB} 180$ from 0.14 to $0.22 \mathrm{ng} / \mathrm{g}$ ww. PBDE 47 was notably higher than the other three measured PBDE congeners followed by PBDE 99, 154 and 153. The content of PBDE 47 ranged from 0.15 to $0.26 \mathrm{ng} / \mathrm{g}$ ww and PBDE 153 ranged from below LOD $(0.005 \mathrm{ng} / \mathrm{g} \mathrm{ww})$ to 0.015 $\mathrm{ng} / \mathrm{g}$ ww. The content of PBDE as a group was lower than PCB with a factor of approximately five. The levels of PCB and PBDE congeners were comparably to a study of Greenland halibut from Northern Norway (Carlsson et al, 2016), but congener patterns differ for some of the congeners. PCB 28 and 52 as well as PBDE 99 contents are relatively higher in this study. However, sources of PCB and PBDE are most likely not the same for Western Greenland and the Northern Norway and this can be the explanation for the difference in patterns. PCB contents of Greenland halibut 2012 - 2013 were analysed by the Danish Veterinary and Food Administration (unpublished results) and the congener pattern were similar to the present study.

PBDE153

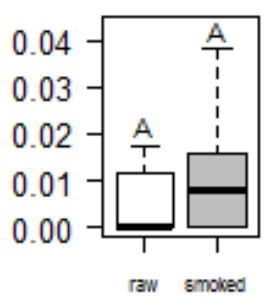

PCB101

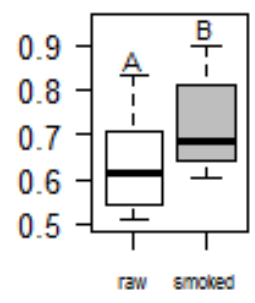

PBDE154

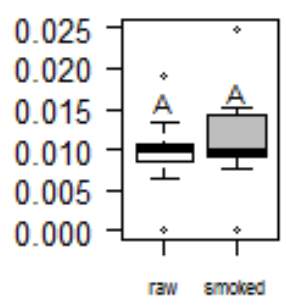

PCB138

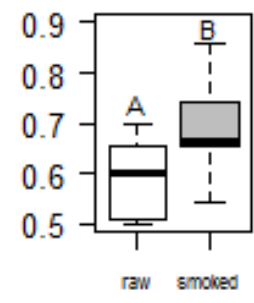

PBDE99

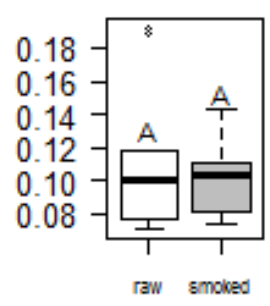

PBDE47

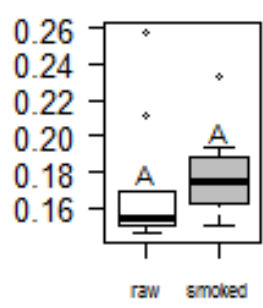

PCB180

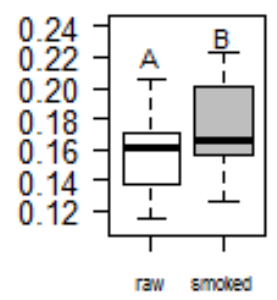

Figure 3. Persistent organic contaminants ( $\mathrm{ng} / \mathrm{g}$ wet weight) in Greenland halibut ( $\mathrm{n}=10$ pairs): Congeners of polybrominated diphenyl ether (PBDE) and polychlorinated biphenyl (PCB) is displayed as a boxplot for raw (white) and smoked (grey) samples processed as paired fish fillets. Observations outside the box and 
hinges are represented by circles. Different letters represent significant differences identified by paired ttest.

For the smoked Greenland halibut the levels of PCB congeners significantly increased (10-22\%) compared to raw Greenland halibut as measured by paired t-test. PBDE contents also had a tendency to increase but they were not statistically significant probably due to the lower levels of PBDE or greater variability of results. The increased levels are probably caused by loss of water during the smoking process. Indeed, when PCB and PBDE levels were corrected for water loss or lipid content, no change in contents were observed after the smoking process. The sum of PCB28, PCB52, PCB101, PCB138, PCB153 and PCB180 (ICES - 6) in raw and smoked Greenland halibut did not exceed the maximum level $(75 \mathrm{ng} / \mathrm{g} \mathrm{ww})$ set for muscle meat of fish (ECR, 2011).

\subsection{Prawns}

Figure 4 illustrates the element concentration of iAs, As, Cd, Cr, Cu, Fe, Zn, Se and Hg in raw, cooked and peeled prawns, respectively, from three seasonal samplings (spring, summer, autumn). The concentration levels of the elements $\mathrm{iAs}, \mathrm{As}, \mathrm{Cd}$, Se and $\mathrm{Hg}$ in the present study were at comparable levels with previously reported figures (Chen, 2009). Processing was a significant factor for all elements in the statistical (GLM) model and interaction between seasons and processing was often observed. Peeling raw prawns increased the $\mathrm{Hg}$ concentration since $\mathrm{Hg}$ is predominantly found in the meat of prawns (Baishaw et al., 2007). In contrast, peeling significantly reduced the concentration of all other elements including iAs, As, $\mathrm{Cr}, \mathrm{Zn}$, Se and especially $\mathrm{Cd}, \mathrm{Cu}$ and $\mathrm{Fe}$ (paired t-test, $\mathrm{p}<0.05$ ), indicating that a significant proportion of these elements are found in the shell/head/guts fraction. For iAs, As and Cu processing was the only significant factor for the reduction of the concentration. The processing procedure (raw $>$ cooked $>$ peeled) significantly decreased mean prawn levels $(\mathrm{mg} / \mathrm{kg} \mathrm{ww})$ of $\mathrm{iAs}\left(0.017^{\mathrm{A}}>0.014^{\mathrm{AB}}>0.011^{\mathrm{B}}\right)$, As $\left(12.8^{\mathrm{A}}>11.0^{\mathrm{B}}\right.$ $\left.>10.1^{\mathrm{B}}\right)$, and $\mathrm{Cu}\left(5.2^{\mathrm{A}}>3.9^{\mathrm{B}}>1.4^{\mathrm{C}}\right)$ (Figure 4). The peeling process most pronouncedly reduced levels of $\mathrm{Cu}(71 \pm 9 \%), \mathrm{Cd},(98 \pm 1 \%)$ and $\mathrm{Fe}(94 \pm 2 \%)$, here reported with mean and standard derivation of the pairwise reductions (Table 1). The EU maximum level for $\mathrm{Cd}$ in the appendages and abdomen for crustaceans is $0.50 \mathrm{mg} / \mathrm{kg}$ (ECR, 2006). Of the raw prawns analysed here, $33 \%$ had a concentration above the maximum level, however, for the cooked and peeled prawns, Cd level was in all cases below the maximum level. This pronounced $\mathrm{Cd}$ reduction is mainly attributed to the removal of guts, which are known to accumulate $\mathrm{Cd}$ (Stewart et al., 2014), however cooking also contributed to the reduction (34 $\pm 14 \%$ ). Sb level was below LOQ $(<0.0008 \mathrm{mg} / \mathrm{kg} \mathrm{ww})$ except for one cooked autumn prawn $(0.012 \mathrm{mg} / \mathrm{kg} \mathrm{ww})$ and $\mathrm{Pb}$ levels varied due to laboratory contamination (max. $0.024 \mathrm{~Pb} \mathrm{mg} / \mathrm{kg} w \mathrm{w}$ detected), which hindered any evaluation of processing and seasonal variation for these elements.

Table 1. Reductions of elements for cooked and peeled prawns ( $n=9$, each). Mean and standard derivation (mean \pm sd) of pairwise reductions $\left(\mathrm{C}_{\mathrm{aw}}-\mathrm{C}_{\text {processed }}\right) / \mathrm{c}_{\text {raw }}$ ) reported in percentage (\%) after removal of clear processing outliers (see Table S10.). Initial levels of raw reported also as mean and standard derivation in $\mathrm{mg} / \mathrm{kg} \mathrm{ww}$.

\begin{tabular}{lrrrrrrrrr}
\hline & Cr & Fe & Cu & Zn & As & Se & Cd & Hg & iAs \\
\hline Raw (mg/kg ww) & 0.15 & 23 & 5 & 11 & 13 & 0.31 & 0.4 & 0.016 & 0.017 \\
& \pm 0.11 & \pm 13 & \pm 1 & \pm 2 & \pm 6 & \pm 0.09 & \pm 0.2 & \pm 0.007 & \pm 0.005 \\
\hline Cooked reduction (\%) & $23 \pm 16$ & $14 \pm 22$ & $25 \pm 14$ & $7 \pm 7$ & $8 \pm 18$ & $18 \pm 9$ & $34 \pm 14$ & $15 \pm 17$ & $23 \pm 13$ \\
\hline Peeled reduction (\%) & $87 \pm 16$ & $94 \pm 2$ & $71 \pm 9$ & $17 \pm 19$ & $18 \pm 14$ & $34 \pm 15$ & $98 \pm 1$ & $-37 \pm 26$ & $44 \pm 30$ \\
\hline
\end{tabular}

Raw prawns had significantly higher $\mathrm{Cd}, \mathrm{Cr}$, Fe, Se and $\mathrm{Zn}$ content in autumn than in spring, while summer levels were typically intermediate. This trend (spring < summer $<$ autumn) for prawns (mean $\mathrm{mg} / \mathrm{kg} \mathrm{ww}$ ) was most clearly observed for Fe $(12<22<33)$ and $\mathrm{Cr}(0.05<0.12<0.25)$. The Cd level (mean mg/kg ww) in spring (0.23) was significantly lower than in the summer (0.50) and from summer to autumn (0.54) it remains unchanged. The results from the present study are not in concordance with a previous study on herring, where no correlation between $\mathrm{Cd}$ level and season was observed (Frantzen et al., 2015). Furthermore, Frantzen et al. (2015) also reported a significant increase in total As concentration from January-February to April-June followed by unchanged values until August-October. However, in our 
study season was not a significant factor for As concentration in prawns, and our data showed high variation for spring replicates, sampled on three different locations (Supplementary Figure S1 and Table S9)Error! Reference source not found.. It is important to notice that the catching areas varied for the different seasons in the current dataset and was based on few replicates $(n=3)$, which weakens the statistical evaluation.

Cu

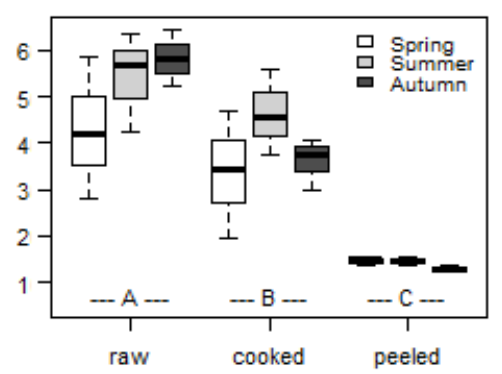

Zn

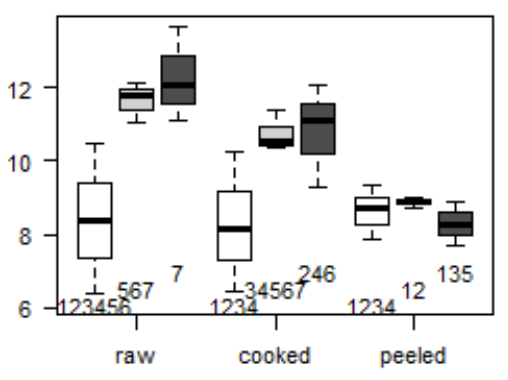

As

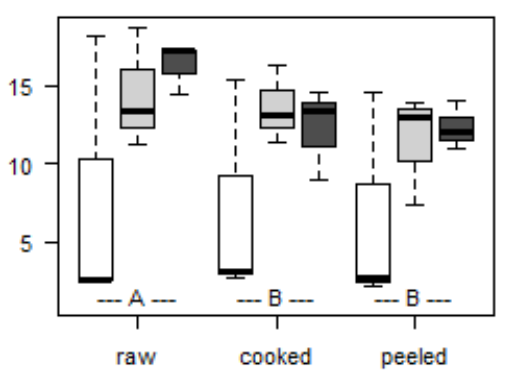

Cd

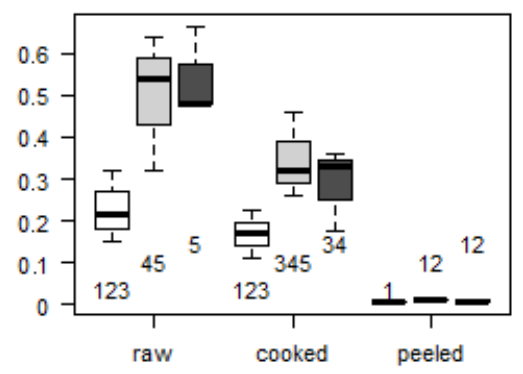

Se

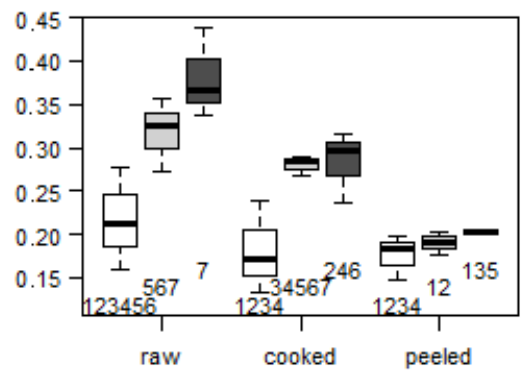

iAs

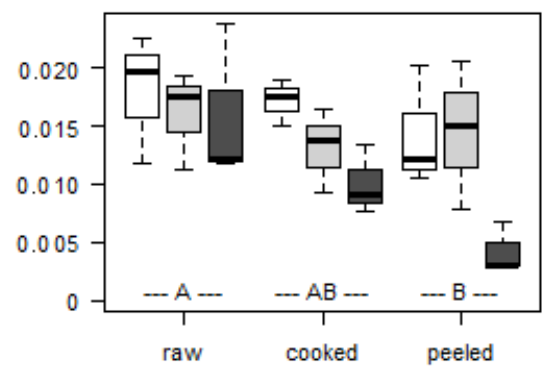

$\mathrm{Fe}$

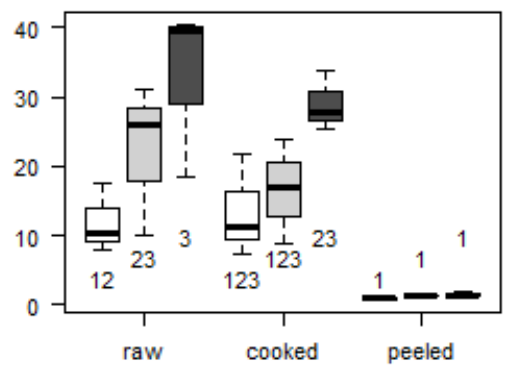

Cr

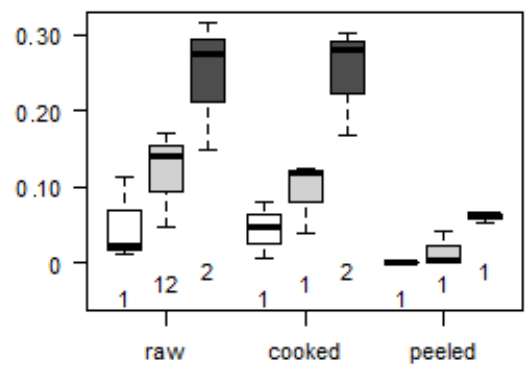

$\mathrm{Hg}$

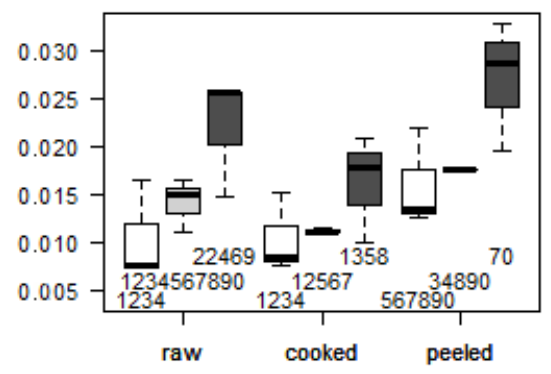

Figure 4. Elements ( $\mathrm{mg} / \mathrm{kg} \mathrm{ww}$ ) in prawns caught at different seasons and processed in different ways (raw, cooked and peeled) is displayed as a boxplot. Each season spring (white), summer (light grey) and autumn (dark grey) included prawn catches $(n=3)$ from different catching fields in Greenland. Different letters indicate effect of a single factor (processing), while different number indicate significant differences for data where season, processing and/or interaction are significant.

\section{Conclusion}

Cold smoking significantly increased the dry matter and lipid content of Greenland halibut. Furthermore PCB congeners and lipid content significantly increased after smoking of Greenland halibut based on wet weight (ww), though not when corrected for water loss. PBDE congener levels were significantly lower than PCB congeners, but PBDE congener levels also had a tendency to increase in smoked Greenland halibut (ww). However, neither PBDE congeners, PFOS nor $\alpha-H B C D$ in Greenland halibut (ww) were significantly changed by smoking. Dry matter, lipid content, element composition (Fe, $\mathrm{Cu}, \mathrm{Zn}, \mathrm{As}, \mathrm{Se}, \mathrm{Cd}, \mathrm{Hg}$ ) and $\alpha-$ 
HBCD of Atlantic salmon and Greenland halibut (ww) were significantly different. The $\alpha$-HBCD level in trimmed fat from smoked Atlantic salmon is similar to raw and smoked Atlantic salmon fillet per lipid weight.

Non-toxic organic As was not transformed to toxic iAs by industrial smoking or cooking of seafood. The iAs levels were low in both raw and smoked Atlantic salmon and Greenland halibut $(<0.003 \mathrm{mg} / \mathrm{kg} \mathrm{ww})$ but slightly higher in raw prawns $(0.017 \pm 0.005 \mathrm{mg} / \mathrm{kg} w w$, mean $\pm \mathrm{sd})$. Element and $\alpha$-HBCD levels were not significantly changed by industrial cold smoking (Greenland halibut) and additional trimming (Atlantic salmon), except for As in Greenland halibut, which was reduced by $17 \%$ (ww) and reductions in total As, $\mathrm{Zn}$ $\mathrm{Hg}$ and $\alpha-H B C D$ in Greenland halibut when based on dry matter or lipid content.

Peeling raw prawns significantly increased $\mathrm{Hg}$ concentration but significantly reduced the concentration of all other elements including iAs, As, Cr, Zn, Se and especially $\mathrm{Cd}$, Cu and Fe. However, interaction between seasons and processing was often observed. Raw prawns had significantly higher contents of $\mathrm{Cd}$, $\mathrm{Fe}, \mathrm{Zn}$, Se and $\mathrm{Cr}$ in autumn than in spring, while summer levels typically were intermediate. The measured contaminants were lower than the current EU maximum levels in seafood.

\section{Acknowledgements}

We thank Alexandra Kuznetsova for excellent statistical advice and Birgitte Koch Herbst, Annette Landin, Vera Lykkerask Berg, Anni Helleskov and Kristine Hjorth Andersen for comprehensive technical assistance. The research leading to these results has received funding from the European Union Seventh Framework Programme (FP7/2007-2013) under the ECsafeSEAFOOD project (grant agreement $\mathrm{n}^{\circ} 311820$ ).

\section{References}

Ásmundsdóttir AM, Baldursdóttir V, Rabieh S, Gunnlaugsdóttir H (2008) Undesirable substances in seafood products - Results from monitoring activities in 2006, Matis - Food Research, Innovation \& Safety, Iceland (issn 1670-7192). Online; http://www.matis.is/media/matis/utgafa/Skyrsla 17-08 net.pdf (accessed 29.8.2016).

Baishaw, S., Edwards, J., Daughtry,B., Ross K. (2007). Mercury in seafood: Mechanisms of accumulation and consequences for consumer health. Reviews on Environmental Health, 22, 91-113.

Bates D., Maechler M, Bolker B, Walker S (2015). Fitting Linear Mixed-Effects Models Using Ime4. Journal of Statistical Software, 67(1), 1-48. doi:10.18637/jss.v067.i01

Birkeland, S., Rørå, A. M. B., Skåra, T., Bjerkeng, B. (2004). Effects of cold smoking procedures and raw material characteristics on product yield and quality parameters of cold smoked Atlantic salmon (Salmo salar L.) fillets.Food Research International, 37(3), 273-286.

Bocio, A., Nadal, M.,Domingo, J. (2005) Human exposure to metals through the diet in Tarragona,Spain. Temporal Trend.Biol.Trace Elem.Res.104,193-201.

Carlsson, P., Herzke, D., Kallenborn, R. (2014) Polychlorinated biphenyls (PCBs), polybrominated diphenyl ethers (PBDEs) and perfluorinated alkylated substances (PFASs) in traditional sea-food items from Western Greenland. Environ. Sci. Pollut. Res. 21, 4741-4750.

Carlsson, P., John D. Crosse, J.D., Halsall, C., Evenset, A., Eldbjørg S. Heimstad, E.S., Harju, M., (2016). Perfluoroalkylated substances (PFASs) and legacy persistent organic pollutants (POPs) in halibut and shrimp from coastal areas in the far north of Norway: Small survey of important dietary foodstuffs for coastal communities. Marine Pollution Bulletin 105, 81-87.

CEN (2016) EN (16802:2016) issued by European Committee for Standardization

Chen, J. M., Yang, Z. Y., Jiang, J., \& Zha, L. W. (2009). Determination and Distribution of Heavy Metals in Different Parts of Pandalus borealis. Food Science, 30 (14), 264-268.

De la Guardia, M., \& Garrigues, S. (2015). Handbook of mineral elements in food. John Wiley \& Sons, Chapter 2 "Dietary intake of minerals", Zand N, Christides T. and Loughrill E, p. 23

Dehouck P, Dabrio M, Cordeiro F, Cizek-Stroh A, de la Calle B; IMEP-42: Determination of PFASs in fish. Interlaboratory Comparison Report; EUR 27579 EN; doi: 10.2787/063168, ISBN 978-92-79-53884-1. https://ec.europa.eu//rc/sites/default/files/JRC\%20Technical\%20Report\%20-\%20IMEP-42.pdf [Cited 2016.06.29.] 
Dietz R, Riget F, Johansen P (1996) Lead, cadmium, mercury and selenium in Greenland marine animals, Sci Total Environ, 186, pp. 67-93.

ECR (2006), European Commission Regulation no 1881/2006 of 19 December 2006 setting maximum levels for certain contaminants in foodstuffs, Official journal L364, 5-, as amended.

ECR (2011), European Commission Regulation no 1259/2011 of 2 December 2011 amending regulation (EC) No 1881/2006 as regards maximum levels for dioxins, dioxin-like PCBs and non dioxin-like PCBs in foodstuffs. Official Journal of the European Union L320/18 03.12.2011.

Education place (2016) "Northern Hemisphere" map [Downloaded 9 August 2016], http://www.eduplace.com/ss/maps/pdf/n_hemis.pdf

EFSA (European Food Safety Authority) (2009). Scientific opinion on arsenic in food. EFSA Journal 2009; 7(10):1351 [199 pp.]. DOI: 10.2903/j.efsa.2009.1351

EFSA (European Food Safety Authority) (2012). Scientific opinion on the risk for public health related to the presence of mercury and methylmercury in food. EFSA Journal 2012;10(12):2985 [241 pp.]. DOI:

10.2903/j.efsa.2012.2985

FAO (2014). The State of World Fisheries and Aquaculture - Opportunities and challenges. Food and Agriculture Organization of the United Nations, Rome. Italy. (available at: http://www.fao.org/3/a-i3720e.pdf (last accessed 30/08/2016).

FAO/WHO (2003).Diet, nutrition and the prevention of chronic diseases. Geneva: Report of a joint WHO/FAO expert consultation. WHO Technical Report Series, No. 916, Geneva, Switzerland (available at WHO Technical Report Series, No. 916 (last accessed 30/08/2016).

Frantzen, S., Maage, A., Duinker, A., Julshamn, K., \& Iversen, S. A. (2015). A baseline study of metals in herring (Clupea harengus) from the Norwegian Sea, with focus on mercury, cadmium, arsenic and lead. Chemosphere, 127, 164-170. doi:10.1016/j.chemosphere.2015.01.037

Glasius, M., Christensen, J.H., Platzz, J., Vorkamp, K. (2005). Halogenated organic contaminants in marine fish and mussels from southern Greenland-pilot study on relations to trophic levels and local sources. J. Environ . Monit., 7, 127-131.

Julshamn, K., Frantzen, S., Valdersnes, S., Nilsen, B., Maage, A., \& Nedreaas, K. (2011) .Concentrations of mercury, arsenic, cadmium and lead in Greenland halibut (Reinhardtius hippoglossoides) caught off the coast of northern Norway. Marine Biology Research 7(8), 733-745.

Julshamn, K., Nilsen, B. M., Frantzen, S., Valdersnes, S., Maage, A., Nedreaas, K., \& Sloth, J. J. (2012). Total and inorganic arsenic in fish samples from Norwegian waters. Food Additives and Contaminants: Part B, 5(4), 229-235.

Karl, H., \& Ruoff, U. (2008). Changes in concentrations of dioxins and dioxin-like PCBs during processing of fish. European Food Research and Technology,226(5), 1175-1181.

Kuznetsova A, Brockhoff PB and Christensen RHB (2016) ImerTest: Tests in Linear Mixed Effects Models. R package version 2.0-30. https://CRAN.R-project.org/package=ImerTest

Lenth R (2016). Least-Squares Means: The R Package Ismeans. Journal of Statistical Software, 69(1), 133. doi:10.18637/jss.v069.i01

Llobet, J.,Falco,G.,Casas,C.,Teixido,A.,Domingo,J. (2003). Concentrations of arsenic, cadmium, mercury, and lead in common foods and estimated daily intake by children,adolescents, adults, and seniors of Catalonia, Spain. J.Agric. Food Chem.51,838-842.

Long, G. L., \& Winefordner, J. D. (1983). Limit of detection. A closer look at the IUPAC definition. Analytical Chemistry, 55(7), 712A-724A.

MSFD (2010). Marine Strategy Framework Directive - Descriptor 9 - Contaminants in fish and other seafood (available at http://mcc.jrc.ec.europa.eu/documents/201406241428.pdf (last accessed 30/08/2016).

NMKL (2002) Nordic Committee on Food Analysis, Dry matter in foodstuffs. The vacuum method. NMKL standard 169, 2002. http://www.nmkl.org/index.php/en/webshop/item/torstof-i-levnedsmidlervakuummetoden-nmkl-169-2002, (accessed 30.8.2016).

Nøstbakken, O.J., Hove, H.T., Duinker, A., Lundebye, A-K. Berntssen, M.H.G., Hannisdal, R., Lunestad, B.T., Maage, A. Madsen, L., Torstensen, B.E. and Julshamn, K. (2015), Contaminant levels in Norwegian 
farmed Atlantic salmon (Salmo salar) in the 13-year period from 1999 to 2011, Environment International, 74, 274-280

R Core Team (2015). R: A language and environment for statistical computing. R Foundation for Statistical Computing, Vienna, Austria. URL https://www.R-project.org/

Rasmussen, R. R., Hedegaard, R. V., Larsen, E. H., \& Sloth, J. J. (2012). Development and validation of an SPE HG-AAS method for determination of inorganic arsenic in samples of marine origin. Analytical and bioanalytical chemistry, 403(10), 2825-2834.

Riget F, Christensen J and Johansen P (2003). AMAP Greenland and the Faroe Islands 1997-2001. The Environment of Greenland Vol. 2, Danish Cooperation for Environment in the Arctic (DANCEA), Denmark. http://www2.mst.dk/udgiv/publications/2003/87-7972-449-3/pdf/87-7972-450-7.pdf (Accessed 29.8.2016)

Sloth JJ (2015) Report on Collaborative Trial FoodStuffs - Determination of Inorganic Arsenic in Food of Marine and Plant Origin, CEN/TC 275/WG10 Elements and their chemical. National Food Institute, Technical University of Denmark, ISBN: 978-87-93109-57-5. http://www.food.dtu.dk/english//media/Institutter/Foedevareinstituttet/Publikationer/Pub-2015/Report on Collaborative Trial Foodstuffs.ashx [Cited 2016.06.29.]

Stahl,T., Mattern, D., Brunn, H. (2011). Review, Toxicology of perfluorinated compounds. Environmental Sciences Europe, 23, 38-52.

Stewart,I., Tan, J., Kenyon R., Kiermeier,A., Malhi N., Sehmbi A, McLeod C. (2014) 2012-13 Survey of Australian Wild-Caught Prawns for Analysis of Cadmium and Selenium, Project No. 2009/787 ISBN: 978-1921563-59-1.

UNEP 2017. Biennial global interlaboratory assessment of persistent organic pollutants, $3^{\text {rd }}$ round 2016. draft results January 2017. , http://drustage.unep.org/chemicalsandwaste/what-we-do/scienceandrisk/pops/pops-monitoring/pops-interlaboratory-assessments (accessed 13.02.2017), 2017.

Van Leeuwen, S. P. J., Van Velzen, M. J. M., Swart, C. P., Van der Veen, I., Traag, W. A., \& De Boer, J. (2009). Halogenated contaminants in farmed salmon, trout, tilapia, pangasius, and shrimp. Environmental science \& technology, 43(11), 4009-4015.

Vandermersch G., Lourenço H. M., Alvarez-Muñoz D., Cunha S., Diogène J., Cano-Sancho G., Sloth J.J., Kwadijk C., Barcelo D., Allegaert W., Bekaert K., Fernandes J.O , Marques A., Robbens J. (2015), Environmental contaminants of emerging concern in seafood - European database on contaminant levels, Environmental Research, 143, 29-45.

Wit,C.A., Herzke ,D., Vorkamp, K. (2010). Brominated flame retardants in the Arctic environment — trends and new candidates. Science of the Total Environment 408, 2885-2918 


\section{Supplementary}

\subsection{Fishing areas in Greenland}

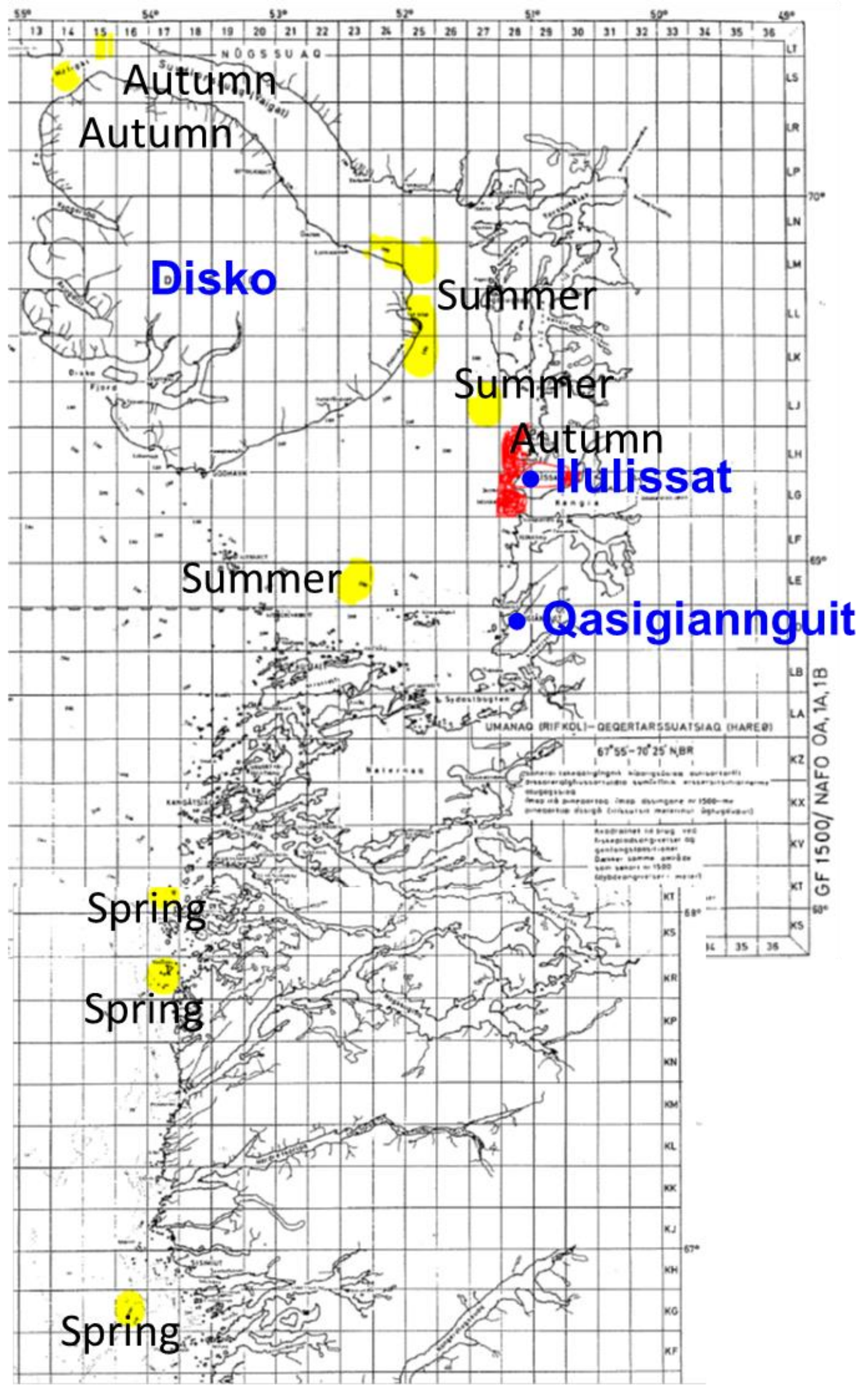

Figure S1. Specific catching areas for Greenland halibut (read area) and prawns (yellow areas, caught at different seasons) in the FAO 21 major fishing area; subarea NAFO $1 \mathrm{~A}$ and $1 \mathrm{~B}$ with grids. 


\subsection{Chemical analysis}

\subsubsection{BFRs and PCBs}

The $\alpha$-hexabromocyclododecane ( $\alpha$-HBCD), $\beta$-HBCD, $\gamma$-HBCD, 2,4,6-tribromophenol (2,4,6-TBP) and tetrabromobisphenol A (TBBPA) were determined both in Greenland halibut and Atlantic salmon by liquid chromatography tandem mass spectrometry (LC-MS/MS). The polybrominated diphenyl ether (PBDE) congeners (PBDE 47, PBDE 99, PBDE 154, PBDE 153) and polychlorinated biphenyls (PCB) congeners (PCB 28, PCB 52, PCB 101, PCB 153, PCB 138, PCB 180) were determined in Greenland halibut by gas chromatography high-resolution mass spectrometry (GC-HRMS).

Both the GC and LC analyses employed the same extraction as the lipid determination. One fourth of the extract was used for GC analyses and half the soxhlet extract for LC analyses using the same cleanup method: The lipid residue from gentle vacuum evaporation was dissolved in $2.0 \mathrm{~mL}$ internal standard solution in hexane and cleaned up in $10 \mathrm{~mL}$ concentrated sulphuric acid by turning the centrifuge tube 20 times. After centrifuging the cleaned hexane phase is further cleaned with $10 \mathrm{~mL}$ milliQ water and evaporated using a gentle stream of nitrogen until $300 \mu \mathrm{L}$ hexane phase is left. For LC analyses then 400 $\mu \mathrm{L}$ methanol is added and the evaporation using nitrogen continues until $200 \mu \mathrm{l}$ sample is left, which is transferred to HPLC vials. For GC analyses the solvent is evaporated to $200 \mu \mathrm{l}$ and transferred to GC-vials.

LC-MS/MS detection was performed on an Agilent HPLC (Agilent Technologies, Santa Clara, US-CA) coupled to a Micromass Quatro ultima tandem mass spectrometer (Waters, Hertfordshire, UK). The separation of $15 \mu \mathrm{l}$ of the analytes was made on a Kinetex C18-HPLC column $2.6 \mu \mathrm{m}, 100 \times 2.1 \mathrm{~mm}$ (Phenomenex, Værløse, Danmark) with Ultra HPLC inline filter using a gradient of $0.01 \%$ acetic acid (A) and methanol (B) at a flow of $0.2 \mathrm{~mL} / \mathrm{min}$ : at $0 \mathrm{~min} .50 \% \mathrm{~B}, 10-23 \mathrm{~min} .95 \% \mathrm{~B}, 33 \mathrm{~min} .50 \% \mathrm{~B}$. The 'MS source' temperature was set to $120^{\circ} \mathrm{C}$ and the 'MS desolvation' temperature to $380^{\circ} \mathrm{C}$. The collision energy was $35 \mathrm{eV}$ and the argon collision gas pressure 2.3e-3mbar. The transitions $(\mathrm{m} / \mathrm{z})$ for quantification were: $\alpha, \beta, \gamma$-HBCD 640.7>81.0; internal standard ${ }^{13} \mathrm{C}_{12} \alpha$-HBCD 653.6>81.0 and 2,4,6-TBP 330.8>81, TBBPA 541.7>446.8; internal standard ${ }^{13} \mathrm{C}_{12}$-TBBPA 553.7>428.8. Both retention time match and ion-ratio were required for detection.

The GC-High resolution MS detection was performed on a Waters Autospec Premier magnetic sector instrument in electron impact ionisation mode (EI), monitoring in selected ion recording (SIR) at 10,000 resolution. Two ion fragments were monitored for each of the analysed PCB and PBDE congeners from the chlorine and bromine isotope cluster, respectively. Monitored mass fragments (m/z): PCB 28: 255.9614 and 257.9584. C13 PCB 28: 268.0016 and 269.9986. PCB 52: 289.9224 and 291.9195. C13 PCB 28: 301.9626 and 303.9596. PCB 101: 323.8834 and 325.8804. C13 PCB 101: 335.9236 and 337.9206. PCB 138 and 153: 359.8415 and 361.8385. C13 PCB 138 and 153: 371.8817 and 373.8781.PCB 180: 393.8025 and 395.7995. C13 PCB 180: 405.8428 and 407.8398. PBDE 47: 483.7132 and 485.7111. C13 PBDE 47: 495.7534 and 497.7514. PBDE 99: 403.7870 and 404.9761. C13 PBDE 99: 415.8272 and 417.8252. PBDE 153 and 154: 481.6975 and 483.6955. C13 PBDE 153 and 154: 493.7378 and 495.7357. The MS conditions were ion source temperature $260^{\circ} \mathrm{C}$, Electron energy $40 \mathrm{eV}$, trap $650 \mu \mathrm{A}$ and GC/MS- interface temperature $270^{\circ} \mathrm{C}-280^{\circ} \mathrm{C}$. The GC column was a DB-5MS (Agilent Technologies), $60 \mathrm{~m}$, i.d.: $0.25 \mathrm{~mm}$, film thickness: $0.25 \mu \mathrm{m}$. The temperature programme was $90^{\circ} \mathrm{C}$ for $2 \mathrm{~min}$; $20^{\circ} \mathrm{C} / \mathrm{min}$ to $180^{\circ} \mathrm{C} ; 2^{\circ} \mathrm{C} / \mathrm{min}$ to $260^{\circ} \mathrm{C} ; 5^{\circ} \mathrm{C} / \mathrm{min}$ to $320^{\circ} \mathrm{C} ; 320^{\circ} \mathrm{C}$ kept for $10 \mathrm{~min}$. LOD based on signal to noise level of three in the mass fragmentograms was $0.005 \mathrm{ng} / \mathrm{g}$ wet weight (ww) for PCB and PBDE congeners, except for PBDE 47 where it was $0.01 \mathrm{ng} / \mathrm{g} \mathrm{ww}$.

The LC-MS/MS method for BFCs is validated (unpublished report) and accredited by the Danish accreditation body DANAK. a-HBCD merits from the validation includes high accuracy and precision for spiked Atlantic salmon ( $\mathrm{n}=27) ; 97 \%$ recovery and $15 \%$ repeatability at $1 \mathrm{ng} / \mathrm{g} \mathrm{ww}$ and $91 \%$ recovery and $16 \%$ repeatability at $0.33 \mathrm{ng} / \mathrm{g}$ ww. The LOD of 2,4,6-TBP was $0.28 \mathrm{ng} / \mathrm{g}$ ww while the others were detectable above $0.05 \mathrm{ng} / \mathrm{g}$ ww. Also intercomparison results of a-HBCD was in agreement with the UNEP global interlaboratory assessment of persistent organic pollutants, $3^{\text {rd }}$ round 2016 (UNEP 2017). 


\subsubsection{Perfluorinated compound (PFC)}

Perfluorinated compounds (PFCs), including perfluorooctane sulfonate (PFOS), perfluorooctanoate (PFOA), perfluorononanoate (PFNA), perfluorooctane sulfonamide (PFOSA) were determined in Greenland halibut by LC-MS/MS.

An aliquot of the homogenized and spiked food samples, (corresponding to $100 \mathrm{mg}$ fat) $\mathrm{g}$, was extracted with $18 \mathrm{~mL}$ methanol in a PP tube tumbled end-over-end overnight at room temperature. The tube was then centrifuged (Sigma) at $3500 \mathrm{rpm}$ at $5{ }^{\circ} \mathrm{C}$ and the supernatant was transferred to a round bottomed glass flask. After this, $2 \mathrm{~mL}$ water was added and the methanol was evaporated on a Kuderna-Danish evaporator. The pressure was kept at approximately $170 \mathrm{mbar}$. Next, $18 \mathrm{~mL}$ of potassium hydroxide $(0.1 \mathrm{M})$ was added to the extract in order to digest the food matrix and precipitate the fat present in the food. The sample was then saponified ten minutes in an ultrasonic bath and gentle shaking overnight. The Oasis WAX SPE cartridge (6cc, $150 \mathrm{mg}, 30 \mu \mathrm{m}$, Waters Corp.) was pre-conditioned with $4 \mathrm{~mL}$ methanol and $4 \mathrm{~mL}$ water, before loading the sample using a Gilson Aspec Xli automatic sample preparation instrument (Middleton, WI-US). The $\mathrm{pH}$ was at this point adjusted to 3.5 with formic acid in the sample, and the sample was loaded on the SPE cartridge. After the loading, the cartridge was washed with $4 \mathrm{~mL}$ ammonium acetate $(25 \mathrm{mM}, \mathrm{pH}$ 4.5), and the sample was eluted with $6 \mathrm{~mL} \mathrm{1 \%}$ ammonium hydroxide in methanol. The eluate was transferred to HPLC vials for LC-MS/MS detection. The general MS settings were the same as for the HBCDs. The HPLC gradient of $2 \mathrm{mM}$ ammonium acetate in milliQ water (A) and $2 \mathrm{mM}$ ammonium acetate in methanol (B) at a flow of $0.3 \mathrm{~mL} / \mathrm{min}$ was: at $0 \mathrm{~min} .35 \% \mathrm{~B}, 15 \mathrm{~min} .100 \% \mathrm{~B}$. The transitions $(\mathrm{m} / \mathrm{z})$ for quantification were: PFOA 413.1>369.0; ${ }^{13} \mathrm{C}_{4}$-PFOA 417.1>372.0; PFOS 498.9>99.0; ${ }^{13} \mathrm{C}_{4}$-PFOS 502.8>99.0; PFNA 563.1>519; PFOSA 498.1>78.0. The method for perfluorinated compounds is validated (unpublished report) and accredited by the Danish accreditation body DANAK. The LODs were all low; PFOS (0.4 ng/g ww), PFOA (0.5 ng/g ww), PFNA (0.5 ng/g ww) and PFOSA (0.5 ng/g ww). High accuracy and precision for PFOS was obtained (91\% recovery and $14 \%$ repeatability) at a spike level of $1.7 \mathrm{ng} / \mathrm{g} \mathrm{ww}$ $(n=23)$. Furthermore satisfactory results, within the range of acceptance for the PFCs including PFOS were determined by our laboratory in an EU intercomparison on Determination of PFASs in fish (Dehouck P, et al., 2015).

\subsubsection{Total elements}

Water was ultra-purified ( $<18 \mathrm{M} \Omega \mathrm{cm}$ ) using a Milli-Q-Integral system (Merck, Germany) and all reagents used were of per analysis quality or better. Nitric acid $\left(68 \% \mathrm{HNO}_{3}\right)$ and hydrochloric acid $(37 \% \mathrm{HCl})$ (PlasmaPure, SCP Science, Courtaboeuf, France) were used for sample preparation and analysis. Standard stock solutions of arsenic (As), bismuth (Bi), cadmium ( $\mathrm{Cd})$, chromium $(\mathrm{Cr})$, cobber (Cu), indium $(\mathrm{In})$, iron $(\mathrm{Fe})$, lead $(\mathrm{Pb})$, mercury $(\mathrm{Hg})$, rhodium $(\mathrm{Rh})$, selenium $(\mathrm{Se})$, tin $(\mathrm{Sn})$ and zinc $(\mathrm{Zn})$ and were 1000 $\mathrm{mg} / \mathrm{mL}$ (PlasmaCal, SCP Science, Courtaboeuf, France).

Subsamples of homogenized fish, prawns ( $2 \mathrm{~g}$ fresh weight) or certified reference material (CRM) $(0.2 \mathrm{~g}$ dry weight) were digested in closed vessels in a microwave oven (Multiwave 3000, Anton Paar, Graz, Austria) with $4 \mathrm{~mL}$ nitric acid $(65 \% \mathrm{w} / \mathrm{w})$ and $2 \mathrm{~mL}$ MilliQ water. The digests were diluted to a volume of $20 \mathrm{~mL}$ with water. Prior to analysis sample aliquots were further diluted; prawns by 4 times and fish by 5 times and adding also $\mathrm{HCl}$ to obtain $3 \% \mathrm{HNO}_{3}, 1 \% \mathrm{HCl}(\mathrm{c} / \mathrm{v})$ aqueous solutions.

An inductively coupled plasma mass spectrometer (ICP-MS) (Agilent 8800 ICP-QQQ-MS, Santa Clara, USA) equipped with a micromist concentric quartz nebulizer and a Scott type double-pass water-cooled spray chamber was run in nogas $\left(\mathrm{Cd}^{111}, \mathrm{Sn}^{118}, \mathrm{Hg}^{202}, \mathrm{~Pb}^{208}, \mathrm{Bi}^{209}\right)$, helium $\left(\mathrm{Fe}^{56}, \mathrm{Cu}^{63}, \mathrm{Zn}^{66}, \mathrm{Bi}^{209}, \mathrm{In}^{115}\right)$ and oxygen $\left(\mathrm{Cr}^{52-68}, \mathrm{As}^{75-91}, \mathrm{Se}^{78-94}, \mathrm{Bi}^{209-209}\right.$ modes, respectively, with $0.2 \mathrm{sec}$ integration time per mass. Typical plasma conditions were $1550 \mathrm{~W}$ RF power, $15 \mathrm{~L} / \mathrm{min}$ plasma gas, $1.05 \mathrm{~L} / \mathrm{min}$ carrier gas and $0 \mathrm{~L} / \mathrm{min}$ makeup gas. Cell gas flows were $5 \mathrm{~mL} / \mathrm{min}$ for helium and $30 \%$ oxygen with stabilization times of $30 \mathrm{~s}, 10 \mathrm{~s}$ and $30 \mathrm{~s}$ for helium, nogas, and oxygen modes, respectively. Instrument parameters were optimized by autotune in the MassHunter software (Agilent, Santa Clara, USA) using a tune solution $\left(1 \mathrm{ng} / \mathrm{mL}{ }^{7} \mathrm{Li},{ }^{24} \mathrm{Mg}\right.$, ${ }^{59} \mathrm{Co},{ }^{89} \mathrm{Y},{ }^{140} \mathrm{Ce}$ and ${ }^{205} \mathrm{TI}$, Agilent). The auto sampler (ASX-500, Agilent Technologies, Waldbronn, 
Germany) introduced the samples into the ICP-MS with a sample uptake time of $50 \mathrm{sec}$. (0.4 rps) and a stabilization time of $30 \mathrm{sec}(0.1 \mathrm{rps})$. Rinse programme between samples; Port (water) $10 \mathrm{~s}$. (0.2 rps) succeeded by rinse 1 and $2(2 \% \mathrm{HNO} 3 \mathrm{c} / \mathrm{v}) 60 \mathrm{sec}(0.1 \mathrm{rps})$ and $60 \mathrm{sec}(0.4 \mathrm{rps})$, respectively. Internal standard (ISTD) was added on-line ( $5 \mu \mathrm{g} / \mathrm{L} \mathrm{Rh}$, In and $\mathrm{Bi}$ ) via a t-piece using the peristaltic pump. A low calibration standard was repeatedly analysed throughout the sequence. Quantification was done by external linear calibration with standard mix prepared in aqueous $\mathrm{HNO}_{3}+\mathrm{HCl}\left(3 \% \mathrm{HNO}_{3}+1 \% \mathrm{HCl} \mathrm{c} / \mathrm{v}\right)$. Blank samples were always analyzed in the same conditions as the samples and were subtracted to all results before reported. The limit of detection (LOD) was assigned to the detection limit (DL) of the calibration curve $(D L=3 \times$ standard deviation $(\sigma)$ of response at the zero concentration level) and the limit of quantification (LOQ) was calculated as $(3 \times \mathrm{LOD})$.

The LOD and LOQ with all quality control results for the current analysis are presented in Table S2 (prawns) and Table S3 (fish) in the supplementary material. Overall satisfying results were achieved in both prawn and fish analyses. Accuracy and precision was evaluated by the CRM "DORM-4" (Dogfish muscle) from National Research Council of Canada (Ontario, Canada). DORM-4 recoveries were between 86-111\% for prawns and $85-123 \%$ for fish analysis with less than 25\% RSD for all elements except for Sn. The recovery ranges were fine when both certificate range and analysis repeatability was taken into account. However Sn had too high DORM-4 recoveries (133\% and 173\%) maybe because Sn only was calibrated only at one level.

The repeated analysis of fish samples and calibration standard revealed satisfying repeatability of analysis for all elements above the LOQ, except for Cr. High RSD is expected for levels below LOQ. However $\mathrm{Cr}$ levels 5-18 times the LOQ in fish were associated with too high RSD (65-82\%), which shows that the LOQ based on the calibration curve was too low. Instead a LOQ of $0.048 \mathrm{mg} / \mathrm{kg}$ for $\mathrm{Cr}$ is estimated based on the duplicate prawn samples. Pb cannot be determined at LOQ levels in the DTU Food lab due to diffuse contamination. But higher $\mathrm{Pb}$ concentrations are also biased (prawn $0.013 \mathrm{mg} / \mathrm{kg}$, RSD 102\% and smoked Atlantic salmon $0.0074 \mathrm{mg} / \mathrm{kg}, \mathrm{RSD} 145 \%$ ) with high variability. Therefore $\mathrm{Pb}$ is only reported as below the levels determined in the samples.

\subsubsection{Inorganic arsenic}

Determination of inorganic arsenic (iAs) follows the standard (EN 16802:2016) issued by European Committee for Standardization (CEN, 2016). Subsamples (1.0 g ww prawn and fish $0.2 \mathrm{~g} \mathrm{dm} \mathrm{CRM)} \mathrm{were}$ extracted by $10 \mathrm{~mL}$ (aqueous $0.1 \mathrm{M}$ nitric acid, $3 \%$ hydrogen peroxide) at $90^{\circ} \mathrm{C}$ for 1 hour and centrifuged $\left(2,500 \times g, 10{ }^{\circ} \mathrm{C}\right)$ for $10 \mathrm{~min}$. Hydrogen peroxide ensured a quantitative oxidation of arsenite (iAs ${ }^{\prime \prime \prime}$ ) to arsenate $\left(i s^{\vee}\right.$ ) (Rasmussen et al, 2012). Aliquot of the supernatant was removed for arsenic speciation analysis. For more details on extraction and reagents see Maulvault et al. (2015).

The $i \mathrm{As}^{\vee}$ in extract is selectively separated from other arsenic compounds using anion exchange HPLC (High Performance Liquid Chromatography) coupled on-line to the ICP-MS (section 2.5). The outlet of the HPLC column was connected to the ICP-MS nebuliser by a short length of PEEK tubing $(0.13 \mathrm{~mm}$ id). The separation was obtained on a polymer-based strong anion exchange column (Dionex lonPac AS7, $10 \mu \mathrm{m}$, $2 \times 250 \mathrm{~mm}$ ) equipped with a guard column (Dionex IonPac AG7, $10 \mu \mathrm{m}, 2 \times 50 \mathrm{~mm}$ ) by isocratic elution $(0.15 \mathrm{~mL} / \mathrm{min}, 15 \mathrm{~min}$ run time) using an Agilent 1260 series HPLC system with a binary pump and autosampler (Agilent Technologies, Waldbronn, Germany). The mobile phase was prepared weekly by dissolving ammonium carbonate $(50 \mathrm{mM})$ in $3 \%(\mathrm{v} / \mathrm{v})$ aqueous methanol solution followed by adjustment of $\mathrm{pH}$ to 10.3 with $25 \%(\mathrm{v} / \mathrm{v})$ aqueous ammonia and subsequently filtration through a $0.45 \mu \mathrm{m}$ polyvinylidene difluoride filter (Millipore, Denmark) prior to use. Injection volume was $5 \mu \mathrm{l}$.

Data was collected using the Agilent ICP-MS MassHunter 4.2 workstation software (version C.01.02). Typical ICP-MS conditions and tuning were as in section 2.5. Analysis was performed in no gas mode and time-resolved analysis mode monitoring ion traces at $\mathrm{m} / \mathrm{z} 75$ (for ${ }^{75} \mathrm{As}$ ) and $\mathrm{m} / \mathrm{z} 35$ (for ${ }^{35} \mathrm{Cl}$ ) with 1 and 0.08 $s$ integration time per mass, respectively. Chloride and and other major organoarsenic species were 
chromatographically resolved from $\mathrm{As}^{\mathrm{V}}$ and did not interfere with the analysis as ${ }^{40} \mathrm{Ar}^{35} \mathrm{Cl}^{+}($Supplementary Figure S2).

A low calibration standard was repeatedly analysed throughout the sequence. Quantification was done by external linear calibration (range $0.2-20 \mathrm{ng} / \mathrm{mL}$ ) which was prepared in extraction solvent. Blank samples were analyzed together with the samples and were subtracted to all results before reported. LOD was assigned to $3 \times$ standard deviation $(\sigma)$ of response a blank sample ( $n=4$ injections) and the limit of quantification (LOQ) was calculated as $10 \times \sigma$ according to IUPAC guidelines (Long and Winefordner, 1983).

The iAs accuracy was evaluated by DORM-4 (Dogfish muscle) from National Research Council of Canada (Ontario, Canada) and ERM-BC211 (rice) from Institute of Reference Materials and Measurements, (Geel, Belgium) for elements. ERM-BC211 is certified for inorganic arsenic $(0.124+/-0.011 \mathrm{mg} / \mathrm{kg})$. DORM-4 is only certified for total metal but not for inorganic arsenic however a target value for iAs has recently been established in a collaborative trial at $0.270+/-0.040 \mathrm{mg} / \mathrm{kg}$ (mean+/- standard deviation, $\mathrm{N}=13$ ) (Sloth, 2015). In the current analyses recoveries were satisfying (88-117\%) and LOQ $0.0013 \mathrm{mg} / \mathrm{kg} w w$ in fish and prawn (Supplementary Table S1).

\subsubsection{References}

CEN (2016) EN (16802:2016) issued by European Committee for Standardization

Dehouck P, Dabrio M, Cordeiro F, Cizek-Stroh A, de la Calle B; IMEP-42: Determination of PFASs in fish. Interlaboratory Comparison Report; EUR 27579 EN; doi: 10.2787/063168, ISBN 978-92-79-53884-1. https://ec.europa.eu/jrc/sites/default/files/JRC\%20Technical\%20Report\%20-\%20IMEP-42.pdf [Cited 2016.06.29.]

Long, G. L., \& Winefordner, J. D. (1983). Limit of detection. A closer look at the IUPAC definition. Analytical Chemistry, 55(7), 712A-724A.

Maulvault, A.L., Anacleto, P, Barbosa, V, Sloth, J.J, Rasmussen, R.R., Tediosi, A., Fernandez-Tejedor, M. , van den Heuvel, F.H.M,, Kotterman, M, Marques, A.(2015) Toxic elements and speciation in seafood samples from different contaminated sites in Europe. Environ.Res. 143, 72-81.

Rasmussen, R. R., Hedegaard, R. V., Larsen, E. H., \& Sloth, J. J. (2012). Development and validation of an SPE HG-AAS method for determination of inorganic arsenic in samples of marine origin. Analytical and bioanalytical chemistry, 403(10), 2825-2834.

Sloth JJ (2015) Report on Collaborative Trial FoodStuffs - Determination of Inorganic Arsenic in Food of Marine and Plant Origin, CEN/TC 275/WG10 Elements and their chemical. National Food Institute, Technical University of Denmark, ISBN: 978-87-93109-57-5. http://www.food.dtu.dk/english//media/Institutter/Foedevareinstituttet/Publikationer/Pub-2015/Report on Collaborative Trial Foodstuffs.ashx [Cited 2016.06.29.]

UNEP 2017. Biennial global interlaboratory assessment of persistent organic pollutants, 3rd round 2016. draft results January 2017. , http://drustage.unep.org/chemicalsandwaste/what-we-do/scienceandrisk/pops/pops-monitoring/pops-interlaboratory-assessments (accessed 13.02.2017), 2017. 


\subsection{Quality control}

\subsubsection{Inorganic arsenic separation}
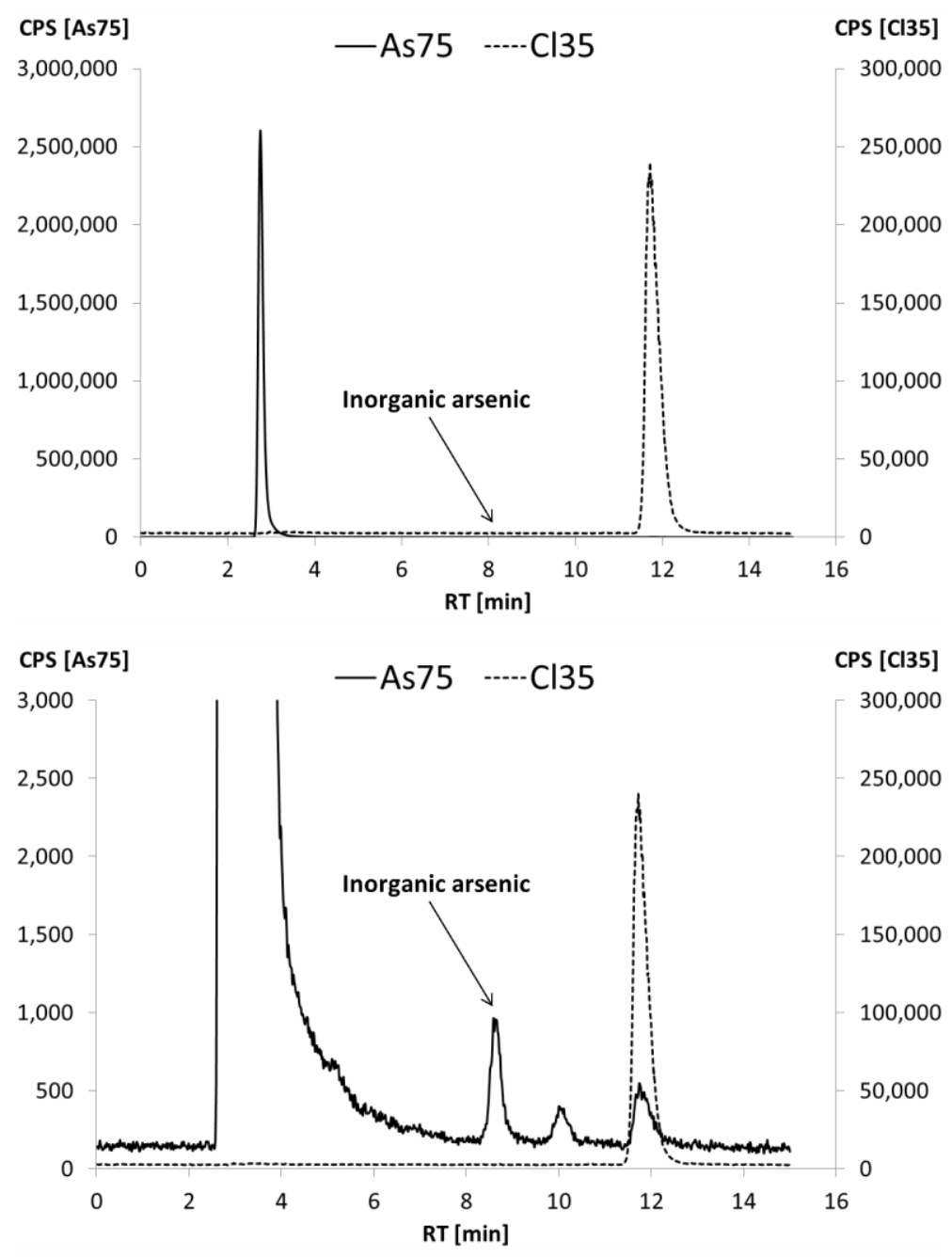

Figure S2. Seperation of arsenic species in a prawn by HPLC-ICP-MS. Counts per second (CPS) for chloride $\left(\mathrm{m} / \mathrm{z}\right.$ Cl ${ }^{35}$ ) and arsenic $\left(\mathrm{m} / \mathrm{z} \mathrm{As}^{75}\right)$ plotted agains time [min]. The inorganic arsenic (8.6 min) peak is small compared to the major organic arsenic peak at $3 \mathrm{~min}$. The minor peak at $10 \mathrm{~min}$ is an organic arsenic species with anionc properties. The chloride that elutes at $12 \mathrm{~min}$ also causes interference in the arsenic trace $\left(\mathrm{m} / \mathrm{z} 75=\mathrm{Cl}^{35}+\mathrm{Ar}^{40}\right)$.

\subsubsection{Inorganic arsenic}

Table S1. Inorganic arsenic (iAs) quality control (QC) for Greenland halibut, Atlantic salmon and prawn, measurements including measured concentrations with relative standard derivation (RSD) and recovery (Rec.). Single extraction of QC samples; "DORM-4" certified reference material (CRM), "BCR 211" CRM and duplicate extractions of two prawn samples, one raw Atlantic salmon, one smoked and one raw Greenland halibut sample. LOD $(0.04 \mathrm{ng} / \mathrm{mL}$ in solution, $0.0004 \mathrm{mg} / \mathrm{kg}$ in fish or prawn), LOQ $(0.13 \mathrm{ng} / \mathrm{mL}$ in solution, $0.0013 \mathrm{mg} / \mathrm{kg}$ in fish or prawn).

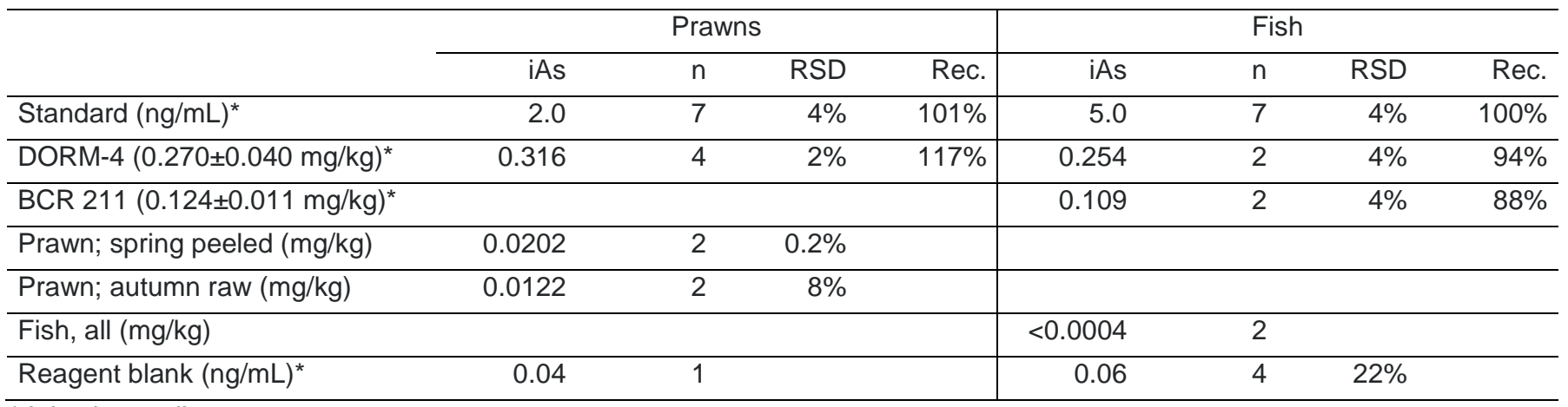

* Injection replicates 


\subsubsection{Total elements}

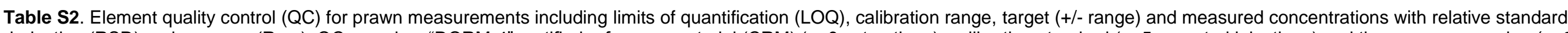

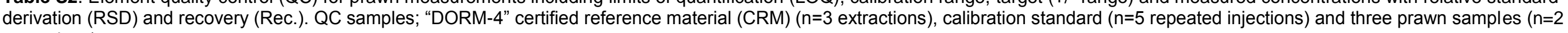
extractions).

\begin{tabular}{|c|c|c|c|c|c|c|c|c|c|c|c|c|c|c|c|c|c|c|}
\hline \multicolumn{7}{|c|}{ Calibration standard } & \multicolumn{3}{|c|}{$\begin{array}{l}\text { Raw prawn } \\
\text { Spring }\end{array}$} & \multicolumn{2}{|c|}{$\begin{array}{l}\text { Raw prawn } \\
\text { Summer }\end{array}$} & \multicolumn{2}{|c|}{$\begin{array}{l}\text { Peeled prawn } \\
\text { Autumn }\end{array}$} & \multicolumn{5}{|c|}{ CRM (DORM-4) } \\
\hline $\begin{array}{l}\text { Element } \\
\text { [ISTD] }\end{array}$ & $\begin{array}{r}L O Q_{\text {solution }} \\
(\mathrm{ng} / \mathrm{mL})\end{array}$ & $\begin{array}{r}\text { Target } \\
(\mathrm{ng} / \mathrm{mL})\end{array}$ & $\begin{array}{r}\text { Measured } \\
(\mathrm{ng} / \mathrm{mL})\end{array}$ & $\begin{array}{r}R S D \\
(\%)\end{array}$ & $\begin{array}{r}\text { Rec. } \\
(\%)\end{array}$ & $\begin{array}{r}\text { Cal range } \\
(\mathrm{ng} / \mathrm{mL})\end{array}$ & $\begin{array}{r}L O Q_{\text {prawn }} \\
(\mathrm{mg} / \mathrm{kg})\end{array}$ & $\begin{array}{c}\text { Mean } \\
(\mathrm{mg} / \mathrm{kg})\end{array}$ & $\begin{array}{r}R S D \\
(\%)\end{array}$ & $\begin{array}{r}\text { Mean } \\
(\mathrm{mgk} / \mathrm{g})\end{array}$ & $\begin{array}{r}R S D \\
(\%)\end{array}$ & $\begin{array}{r}\text { Mean } \\
(\mathrm{mg} / \mathrm{kg})\end{array}$ & $\begin{array}{r}R S D \\
(\%)\end{array}$ & $\begin{array}{l}\text { Extract } \\
(n g / m L)\end{array}$ & $\begin{array}{r}\text { Target } \\
(\mathrm{mg} / \mathrm{kg})\end{array}$ & $\begin{array}{r}\text { Measured } \\
\text { (mg/kg } \\
\text { dry matter) }\end{array}$ & $\begin{array}{r}R S D \\
(\%)\end{array}$ & $\begin{array}{r}R e c . \\
\text { (\%) }\end{array}$ \\
\hline $\mathrm{Cr}[\mathrm{Bi}]$ & 0.6 & 20 & 22 & 12 & 111 & $0.4-20$ & 0.022 & 0.023 & 130 & 0.048 & 9 & 0.053 & 19 & 4.7 & $1.87+/-0.16$ & 2.08 & 18 & 111 \\
\hline $\mathrm{Fe}[\mathrm{Bi}]$ & 1.3 & 260 & 286 & 9 & 110 & $5-100$ & 0.048 & 7.81 & 21 & 10.02 & 5 & 1.88 & 13 & 865 & $341+/-27$ & 353 & 6 & 103 \\
\hline $\mathrm{Cu}[\ln ]$ & 1.0 & 250 & 248 & 6 & 99 & $2-250$ & 0.037 & 2.81 & 0.1 & 4.24 & 0.3 & 1.36 & 8 & 40 & $15.9+/-0.9$ & 16.3 & 1 & 103 \\
\hline$\underline{Z n}[\mathrm{Bi}]$ & 1.0 & 421 & 444 & 8 & 105 & $20-400$ & 0.037 & 6.37 & 7 & 11.03 & 1 & 8.91 & 5 & 133 & $52.2+/-3.2$ & 48.8 & 3 & 93 \\
\hline As [Bi] & 0.05 & 256 & 264 & 6 & 103 & $0.5-1000$ & 0.002 & 2.47 & 2 & 13.37 & 1 & 14.00 & 4 & 17 & $6.8+/-0.64$ & 6.67 & 3 & 98 \\
\hline Se [Bi] & 0.2 & 52 & 55 & 8 & 106 & $0.2-10$ & 0.008 & 0.16 & 6 & 0.27 & 1 & 0.20 & 9 & 9.0 & $3.56+/-0.34$ & 3.80 & 5 & 107 \\
\hline $\mathrm{Cd}[\mathrm{In}]$ & 0.02 & 20 & 19 & 1 & 96 & $0.05-20$ & 0.0006 & 0.149 & 1 & 0.321 & 0.5 & 0.011 & 6 & 0.8 & $0.306+/-0.015$ & 0.319 & 6 & 104 \\
\hline$S n[B i]$ & 0.02 & 0 & ND & ND & ND & 1 & 0.0008 & 0.0003 & 68 & 0.0002 & 78 & 0.00005 & 621 & 0.1 & $0.056+/-0.010$ & 0.074 & 4 & 133 \\
\hline $\mathrm{Hg}[\mathrm{Bi}]$ & 0.02 & 5 & 5 & 2 & 102 & $0.05-2$ & 0.0008 & 0.008 & 32 & 0.011 & 2 & 0.033 & 2 & 1.0 & $0.410+/-0.055$ & 0.360 & 4 & 88 \\
\hline $\mathrm{Pb}[\mathrm{Bi}]$ & 0.02 & 5 & 5 & 1 & 101 & $1-5$ & 0.0008 & 0.0004 & 93 & 0.0130 & 102 & -0.0028 & -4 & 1.1 & $0.416+/-0.053$ & 0.357 & 18 & 86 \\
\hline
\end{tabular}

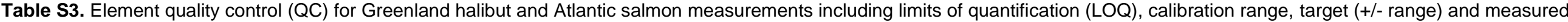

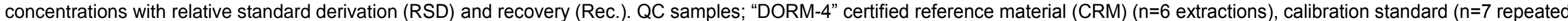
injections) and fish samples ( $n=2-3$ extractions).

\begin{tabular}{|c|c|c|c|c|c|c|c|c|c|c|c|c|c|c|c|c|c|c|}
\hline & Calibration s & tandard & & & & & & $\begin{array}{l}\text { Smoked } \\
\text { salmon } \\
(n=3)\end{array}$ & & $\begin{array}{l}\text { Smoked } \\
\text { Greenlano } \\
\text { halibut ( } n\end{array}$ & & $\begin{array}{l}\text { Raw } \\
\text { Greenlana } \\
\text { halibut }(n=\end{array}$ & & $C R M(D$ & ORM-4) & & & \\
\hline $\begin{array}{l}\text { Element } \\
\text { [ISTD] }\end{array}$ & $\begin{array}{r}L O Q_{\text {solution }} \\
(n g / m L)\end{array}$ & $\begin{array}{r}\text { Target } \\
(n g / m L)\end{array}$ & $\begin{array}{r}\text { Measured } \\
(n g / m L)\end{array}$ & $\begin{array}{r}R S D \\
(\%)\end{array}$ & $\begin{array}{r}\text { Rec. } \\
\text { (\%) }\end{array}$ & $\begin{array}{r}\text { Cal range } \\
(n g / m L)\end{array}$ & $\begin{array}{c}L O Q_{\text {fish }} \\
(\mathrm{mg} / \mathrm{kg})\end{array}$ & $\begin{array}{r}\text { Mean } \\
(\mathrm{mg} / \mathrm{kg})\end{array}$ & $\begin{array}{r}R S D \\
(\%)\end{array}$ & $\begin{array}{r}\text { Mean } \\
(\mathrm{mg} / \mathrm{kg})\end{array}$ & $\begin{array}{r}R S D \\
(\%)\end{array}$ & $\begin{array}{r}\text { Mean } \\
(\mathrm{mg} / \mathrm{kg})\end{array}$ & $\begin{array}{r}R S D \\
(\%)\end{array}$ & $\begin{array}{l}\text { Extract } \\
(n g / m L)\end{array}$ & $\begin{array}{r}\text { Target } \\
(\mathrm{mg} / \mathrm{kg})\end{array}$ & $\begin{array}{r}\text { Measured } \\
\text { (mg/kg dry } \\
\text { matter) }\end{array}$ & $\begin{array}{r}R S D \\
(\%)\end{array}$ & $\begin{array}{r}R e c . \\
(\%)\end{array}$ \\
\hline Cr [none] & 0.07 & 0.8 & 0.8 & 10 & 96 & 0.4-12 & 0.0035 & 0.026 & 65 & 0.017 & 68 & 0.004 & 82 & 4.6 & $1.87+/-0.16$ & 2.11 & 12 & 113 \\
\hline $\mathrm{Fe}[R h]$ & 0.9 & 70 & 75 & 4 & 107 & $35-1050$ & 0.041 & 2.66 & 3 & 0.80 & 8 & 0.54 & 5 & 916 & $341+/-27$ & 418 & 14 & 123 \\
\hline $\mathrm{Cu}[R h]$ & 0.2 & 2 & 2 & 3 & 97 & $1.2-36$ & 0.009 & 0.35 & 7 & 0.11 & 4 & 0.13 & 6 & 40 & $15.9+/-0.9$ & 18.3 & 20 & 115 \\
\hline$Z n[R h]$ & 0.2 & 30 & 30 & 2 & 100 & $15-450$ & 0.008 & 3.97 & 3 & 3.38 & 1 & 3.14 & 5 & 135 & $52.2+/-3.2$ & 61.7 & 17 & 118 \\
\hline As [none] & 0.1 & 50 & 41 & 3 & 81 & $5-150$ & 0.007 & 0.593 & 3 & 2.79 & 3 & 2.43 & 11 & 14 & $6.8+/-0.64$ & 6.39 & 14 & 94 \\
\hline Se [none] & ND & 2 & 2 & 42 & 84 & $1-30$ & ND & 0.13 & 16 & 0.29 & 20 & 0.18 & 29 & 6.6 & $3.56+/-0.34$ & 3.02 & 16 & 85 \\
\hline $\mathrm{Cd}[\mathrm{Rh}]$ & 0.004 & 2 & 2 & 1 & 101 & $0.05-1.5$ & 0.0002 & 0.0001 & 11 & 0.0006 & 4 & 0.0006 & 8 & 0.8 & $0.306+/-0.015$ & 0.366 & 16 & 120 \\
\hline Sn [Rh] & 0.06 & 0 & ND & ND & ND & 1 & 0.0027 & 0.0012 & 30 & 0.0017 & 14 & 0.0011 & 11 & 0.2 & $0.056+/-0.010$ & 0.097 & 22 & 173 \\
\hline $\mathrm{Hg}[\mathrm{Bi}]$ & 0.02 & 0.1 & 0.1 & 4 & 106 & $0.05-1.5$ & 0.0009 & 0.023 & 5 & 0.036 & 6 & 0.035 & 6 & 0.9 & $0.410+/-0.055$ & 0.407 & 13 & 99 \\
\hline $\mathrm{Pb}[\mathrm{Bi}]$ & 0.05 & 0.1 & 0.1 & 7 & 99 & $0.05-1.5$ & 0.0026 & 0.0074 & 145 & 0.0009 & 22 & 0.0009 & 7 & 1.1 & $0.416+/-0.053$ & 0.507 & 25 & 122 \\
\hline
\end{tabular}

21 of 28 


\subsection{Greenland halibut dataset}

Table S4. PCB and PBDE congeners levels (ng/g ww), dry matter (\%), lipid content $(\%, n=2)$ in raw $(A)$ and smoked (B) Greenland halibut $(n=10)$. No data (ND). Mean \pm standard derivation $(n=2)$ is reported for duplicates.

\begin{tabular}{|c|c|c|c|c|c|c|c|c|c|c|c|c|}
\hline \multirow[t]{2}{*}{ pair } & \multirow[t]{2}{*}{$\begin{array}{r}\text { dry } \\
\text { matter }\end{array}$} & \multirow{2}{*}{$\begin{array}{c}\text { Lipid } \\
\% \\
\end{array}$} & \multicolumn{6}{|c|}{ PCB congeners } & \multicolumn{4}{|c|}{ PBDE congeners } \\
\hline & & & 28 & 52 & 101 & 153 & 138 & 180 & 47 & 99 & 154 & 153 \\
\hline $1 \mathrm{~A}$ & 27.4 & $11.0 \pm 0.3$ & 0.578 & 0.428 & 0.508 & 0.748 & 0.501 & 0.115 & 0.146 & 0.076 & 0.011 & 0.000 \\
\hline $2 A$ & 29.8 & $13.2 \pm 1.0$ & 0.556 & 0.487 & 0.546 & 0.829 & 0.527 & 0.137 & 0.150 & 0.073 & 0.006 & 0.000 \\
\hline $3 A$ & 33.0 & $15.1 \pm 1.3$ & 0.556 & 0.447 & 0.576 & 1.254 & 0.689 & 0.206 & 0.158 & 0.090 & 0.010 & 0.000 \\
\hline $4 \mathrm{~A}$ & 29.8 & $12.9 \pm 0.2$ & 0.606 & 0.539 & 0.529 & 0.956 & 0.605 & 0.165 & 0.258 & 0.192 & 0.019 & 0.015 \\
\hline $5 \mathrm{~A}$ & 31.6 & $13.9 \pm 0.0$ & 0.702 & 0.652 & 0.708 & 1.063 & 0.698 & 0.171 & 0.156 & 0.070 & 0.009 & 0.012 \\
\hline $6 \mathrm{~A}$ & 31.7 & $15.9 \pm 0.1$ & 0.673 & 0.578 & 0.693 & 1.054 & 0.653 & 0.176 & 0.154 & 0.118 & 0.010 & 0.017 \\
\hline $7 \mathrm{~A}$ & 30.3 & $13.7 \pm 0.5$ & 0.544 & 0.378 & 0.600 & 0.968 & 0.507 & 0.158 & 0.153 & 0.083 & 0.000 & 0.000 \\
\hline $8 A$ & 29.7 & $13.4 \pm 0.8$ & 0.829 & 0.606 & 0.713 & 0.901 & 0.593 & 0.148 & 0.212 & 0.189 & 0.013 & 0.000 \\
\hline $9 \mathrm{~A}$ & 30.7 & $13.4 \pm 0.2$ & 0.769 & 0.590 & 0.830 & 0.938 & 0.615 & 0.171 & 0.147 & 0.111 & 0.008 & 0.000 \\
\hline $10 \mathrm{~A}$ & 30.4 & $12.5 \pm 0.3$ & 0.602 & 0.518 & 0.625 & 0.791 & 0.507 & 0.124 & 0.170 & 0.113 & 0.010 & 0.000 \\
\hline $1 \mathrm{~B}$ & 33.7 & $13.6 \pm 0.7$ & 0.652 & 0.567 & 0.683 & 1.053 & 0.664 & 0.156 & 0.163 & 0.081 & 0.009 & 0.012 \\
\hline $2 B$ & 32.9 & $15.5 \pm 0.5$ & 0.560 & 0.523 & 0.603 & 0.913 & 0.543 & 0.144 & 0.159 & 0.143 & 0.014 & 0.022 \\
\hline $3 B$ & 35.6 & $17.4 \pm 0.5$ & 0.584 & 0.484 & 0.639 & 1.375 & 0.744 & 0.223 & 0.175 & 0.075 & 0.008 & 0.008 \\
\hline $4 \mathrm{~B}$ & 38.9 & $16.3 \pm 0.9$ & 0.715 & 0.728 & 0.623 & 1.124 & 0.708 & 0.166 & 0.177 & 0.098 & 0.010 & 0.016 \\
\hline $5 B$ & 34.9 & $16.7 \pm 0.4$ & 0.925 & 0.871 & 0.897 & 1.324 & 0.857 & 0.189 & 0.189 & 0.073 & 0.010 & 0.007 \\
\hline $6 B$ & 38.6 & $17.8 \pm 3.2$ & 0.793 & 0.768 & 0.811 & 1.291 & 0.801 & 0.201 & 0.233 & 0.104 & 0.025 & 0.038 \\
\hline $7 B$ & 34.5 & $15.9 \pm 0.2$ & 0.679 & 0.492 & 0.740 & 1.214 & 0.653 & 0.202 & 0.193 & 0.110 & 0.010 & 0.000 \\
\hline $8 B$ & 37.6 & $15.2 \pm 0.4$ & 0.713 & 0.636 & 0.820 & 0.996 & 0.654 & 0.156 & 0.164 & 0.115 & 0.015 & 0.000 \\
\hline $9 \mathrm{~B}$ & 37.5 & $16.9 \pm 0.1$ & ND & ND & ND & ND & ND & ND & ND & ND & ND & ND \\
\hline $10 \mathrm{~B}$ & 34.6 & $16.5 \pm 0.6$ & 0.735 & 0.650 & 0.673 & 0.997 & 0.604 & 0.126 & 0.151 & 0.102 & 0.000 & 0.000 \\
\hline
\end{tabular}

Table S5. Element (mg/kg wet weight), $\alpha-H B C D, 2,4,6-$ TBP and PFOS levels (ng/g ww), dry matter (\%), lipid content (\%) in raw (A) and smoked $(B)$ halibut $(n=10)$. Mean \pm standard derivation $(n=2)$ and pooled relative standard derivation $\left(R S D_{\text {pooled, }}\right.$ excluding outliers $^{*}$ ) are reported for duplicates.

\begin{tabular}{|c|c|c|c|c|c|c|c|c|c|c|c|c|c|}
\hline pair & $\begin{array}{r}\text { dry } \\
\text { matter }\end{array}$ & Lipid & $\mathrm{Fe}$ & $\mathrm{Cu}$ & Zn & As & $\mathrm{Se}$ & Cd & Sn & $\mathrm{Hg}$ & $\alpha-H B C D$ & 2,4,6-TBP & PFOS \\
\hline $1 \mathrm{~A}$ & 27.4 & $11.0 \pm 0.3$ & 0.305 & 0.089 & 2.588 & 3.299 & 0.241 & 0.00075 & 0.0002 & 0.0472 & $0.080 \pm 0.001$ & $0.16 \pm 0.00$ & 0.37 \\
\hline $2 \mathrm{~A}$ & 29.8 & $13.2 \pm 1.0$ & 1.665 & 0.075 & 2.803 & 3.985 & 0.257 & 0.00086 & 0.0005 & 0.0451 & $0.055 \pm 0.004$ & $0.28 \pm 0.05$ & 0.43 \\
\hline $3 A$ & 33.0 & $15.1 \pm 1.3$ & 0.628 & 0.114 & 3.824 & 7.841 & 0.477 & 0.00080 & 0.0006 & 0.101 .9 & $0.061 \pm 0.045^{*}$ & $0.20 \pm 0.11$ & 0.52 \\
\hline $4 \mathrm{~A}$ & 29.8 & $12.9 \pm 0.2$ & 0.617 & 0.089 & 2.759 & 5.425 & 0.222 & 0.00061 & 0.0003 & 0.0476 & $0.061 \pm 0.008$ & $0.24 \pm 0.00$ & 0.43 \\
\hline $5 \mathrm{~A}$ & 31.6 & $13.9 \pm 0.0$ & 0.316 & 0.091 & 2.864 & 3.761 & 0.312 & 0.00056 & 0.0001 & 0.0454 & 0.063 & $0.29 \pm 0.24$ & 0.20 \\
\hline $6 \mathrm{~A}$ & 31.7 & $15.9 \pm 0.1$ & 0.401 & 0.090 & 3.049 & 3.866 & 0.373 & 0.00048 & 0.0009 & 0.0545 & 0.061 & $0.21 \pm 0.16$ & 0.34 \\
\hline $7 \mathrm{~A}$ & 30.3 & $13.7 \pm 0.5$ & 0.454 & 0.093 & 3.007 & 9.041 & 0.312 & 0.00112 & 0.0005 & 0.0669 & $0.046 \pm 0.006$ & $0.09 \pm 0.00$ & 0.52 \\
\hline $8 \mathrm{~A}$ & 29.7 & $13.4 \pm 0.8$ & 0.408 & 0.085 & 3.330 & 5.340 & 0.273 & 0.00087 & 0.0008 & 0.0468 & $0.095 \pm 0.004$ & $0.10 \pm 0.02$ & 0.16 \\
\hline $9 \mathrm{~A}$ & 30.7 & $13.4 \pm 0.2$ & 0.466 & 0.091 & 3.136 & 5.487 & 0.274 & 0.00085 & 0.0011 & 0.0472 & $0.035 \pm 0.006$ & $0.35 \pm 0.03$ & 0.55 \\
\hline $10 \mathrm{~A}$ & 30.4 & $12.5 \pm 0.3$ & 0.413 & 0.111 & 3.117 & 2.430 & 0.180 & 0.00060 & 0.0004 & 0.0344 & $0.032 \pm 0.006$ & $0.13 \pm 0.01$ & 0.22 \\
\hline 1B & 33.7 & $13.6 \pm 0.7$ & 0.610 & 0.101 & 3.150 & 2.864 & 0.228 & 0.00105 & 0.0009 & 0.0474 & $0.064 \pm 0.021$ & $0.21 \pm 0.06$ & 0.32 \\
\hline 2B & 32.9 & $15.5 \pm 0.5$ & 0.457 & 0.105 & 3.041 & 3.261 & 0.392 & 0.00090 & 0.0029 & 0.042 & $0.045 \pm 0.012$ & $0.38 \pm 0.32$ & 0.48 \\
\hline 3B & 35.6 & $17.4 \pm 0.5$ & 0.689 & 0.106 & 3.138 & 6.053 & 0.416 & 0.00059 & 0.0013 & 0.0788 & $0.067 \pm 0.015$ & $0.37 \pm 0.34$ & 0.61 \\
\hline 4B & 38.9 & $16.3 \pm 0.9$ & 0.756 & 0.105 & 3.081 & 4.561 & 0.205 & 0.00066 & 0.0006 & 0.0454 & $0.080 \pm 0.025$ & $0.28 \pm 0.06$ & 0.44 \\
\hline $5 B$ & 34.9 & $16.7 \pm 0.4$ & 0.489 & 0.087 & 2.937 & 3.329 & 0.197 & 0.00071 & -0.0004 & 0.044 & 0.077 & $0.34 \pm 0.14$ & 0.18 \\
\hline $6 \mathrm{~B}$ & 38.6 & $17.8 \pm 3.2$ & 0.756 & 0.109 & 3.983 & 4.135 & 0.364 & 0.00054 & 0.0014 & 0.0592 & $0.049 \pm 0.006$ & $0.24 \pm 0.06$ & 0.57 \\
\hline 7B & 34.5 & $15.9 \pm 0.2$ & 0.619 & 0.098 & 2.995 & 8.228 & 0.381 & 0.00095 & 0.0012 & 0.0626 & $0.032 \pm 0.004$ & $0.17 \pm 0.10$ & 0.43 \\
\hline 8B & 37.6 & $15.2 \pm 0.4$ & 0.581 & 0.111 & 3.133 & 2.980 & 0.313 & 0.00104 & 0.0006 & 0.0392 & $0.055 \pm 0.016$ & $0.13 \pm 0.02$ & 0.26 \\
\hline $9 B$ & 37.5 & $16.9 \pm 0.1$ & 0.445 & 0.083 & 3.008 & 3.886 & 0.130 & 0.00061 & 0.0016 & 0.0398 & $0.036 \pm 0.002$ & $0.44 \pm 0.15$ & 0.37 \\
\hline $10 \mathrm{~B}$ & 34.6 & $16.5 \pm 0.6$ & 0.669 & 0.091 & 3.355 & 2.786 & 0.292 & 0.00056 & 0.0009 & 0.0356 & $0.031 \pm 0.004$ & $0.12 \pm 0.01$ & 0.39 \\
\hline \multicolumn{2}{|c|}{$\mathrm{RSD}_{\text {pooled }}$} & $6 \%$ & & & & & & & & & $19 \%$ & $47 \%$ & \\
\hline
\end{tabular}




\subsection{Atlantic salmon dataset}

Table S6. Element (mg/kg wet weight), $\alpha-H B C D$ and 2,4,6-TBP (ng/g fish ww or lipid), dry matter (\%), lipid content (\%) in raw (A) and smoked (B) Atlantic salmon fillet and smoked Atlantic salmon fat $(C)(n=4)$. Mean \pm standard derivation $(n=2)$ and pooled relative standard derivation $\left(R S D_{\text {pooled, }}\right.$ excluding outliers *) are reported for duplicates.

\begin{tabular}{|c|c|c|c|c|c|c|c|c|c|c|c|c|}
\hline pair & dry matter & lipid & $\mathrm{Fe}$ & $\mathrm{Cu}$ & $\mathrm{Zn}$ & As & $\mathrm{Se}$ & Cd & Sn & $\mathrm{Hg}$ & $\alpha-H B C D$ & 2,4,6-TBP \\
\hline $1 \mathrm{~A}$ & 51.0 & $19.5 \pm 1.3$ & 2.177 & 0.290 & 3.606 & 0.648 & 0.042 & 0.00002 & 0.0003 & 0.0178 & $0.173 \pm 0.005$ & $0.41 \pm 0.07$ \\
\hline $2 A$ & 49.3 & $20.6 \pm 1.0$ & 3.519 & 0.398 & 4.830 & 0.744 & 0.102 & 0.00010 & 0.0005 & 0.0211 & $0.195 \pm 0.038$ & $0.08 \pm 0.11^{*}$ \\
\hline $3 A$ & $53.5 \pm 0.5$ & $22.4 \pm 2.0$ & 2.100 & 0.328 & 3.529 & 0.629 & 0.069 & 0.00013 & 0.0005 & 0.0170 & $0.203 \pm 0.035$ & $0.24 \pm 0.06$ \\
\hline $4 \mathrm{~A}$ & 42.0 & $17.6 \pm 0.5$ & 2.631 & 0.383 & 4.287 & 0.593 & 0.122 & 0.00025 & 0.0001 & 0.0254 & $0.153 \pm 0.021$ & $0.17 \pm 0.03$ \\
\hline $1 \mathrm{~B}$ & 51.9 & $20.4 \pm 0.2$ & 3.048 & 0.368 & 4.306 & 0.708 & 0.112 & 0.00002 & 0.0004 & 0.0213 & $0.194 \pm 0.025$ & $0.35 \pm 0.00$ \\
\hline $2 B$ & 48.7 & $19.3 \pm 0.1$ & 2.620 & 0.301 & 3.785 & 0.531 & 0.080 & 0.00003 & 0.0000 & 0.0209 & $0.185 \pm 0.052$ & $0.17 \pm 0.01$ \\
\hline 3B & 51.7 & $20.6 \pm 1.5$ & 3.037 & 0.388 & 3.981 & 0.567 & 0.142 & 0.00006 & 0.0003 & 0.0190 & $0.196 \pm 0.030$ & $0.19 \pm 0.02$ \\
\hline 4B & $47.1 \pm 0.7$ & $18.8 \pm 0.9$ & 2.521 & 0.330 & 3.945 & 0.593 & 0.134 & 0.00009 & 0.0004 & 0.0228 & $0.201 \pm 0.037$ & $0.15 \pm 0.02$ \\
\hline $1 \mathrm{C}$ & & 97.8 & & & & & & & & & & 0.96 \\
\hline $2 \mathrm{C}$ & & 101.1 & & & & & & & & & 0.972 & 0.90 \\
\hline $3 C$ & & 95.9 & & & & & & & & & 0.802 & 1.07 \\
\hline $4 C$ & & 97.6 & & & & & & & & & 0.861 & 1.22 \\
\hline
\end{tabular}

$R S D_{\text {pooled }}$

$17 \%$

$15 \%$ 


\subsection{Reductions Atlantic salmon and Greenland halibut}

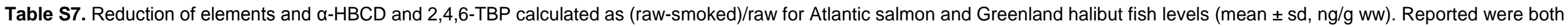
mean reduction and individual reductions pairs (mean $\pm \mathrm{sd}$ ) for comparison.

\begin{tabular}{|c|c|c|c|c|c|c|c|c|}
\hline Atlantic salmon & $\begin{array}{l}\text { dry } \\
\text { matter }\end{array}$ & Lipid & $\mathrm{Fe}$ & $\mathrm{Cu}$ & $\mathrm{Zn}$ & As & $\mathrm{Se}$ & Cd \\
\hline Unit & $\%$ & $\%$ & $\mathrm{mg} / \mathrm{kg}$ & $\mathrm{mg} / \mathrm{kg}$ & $\mathrm{mg} / \mathrm{kg}$ & $\mathrm{mg} / \mathrm{kg}$ & $\mathrm{mg} / \mathrm{kg}$ & $\mathrm{mg} / \mathrm{kg}$ \\
\hline Raw (ng/g ww) & $49.0 \pm 4.9$ & $20.0 \pm 2.0$ & $2.6 \pm 0.7$ & $0.35 \pm 0.05$ & $4.1 \pm 0.6$ & $0.65 \pm 0.07$ & $0.08 \pm 0.04$ & $0.00012 \pm 0.00010$ \\
\hline Smoked (ng/g ww) & $49.9 \pm 2.3$ & $19.8 \pm 0.9$ & $2.8 \pm 0.3$ & $0.35 \pm 0.04$ & $4.0 \pm 0.2$ & $0.60 \pm 0.08$ & $0.12 \pm 0.03$ & $0.00005 \pm 0.00003$ \\
\hline Reduction (mean) & $-2 \%$ & $1 \%$ & $-8 \%$ & $1 \%$ & $1 \%$ & $8 \%$ & $-40 \%$ & $59 \%$ \\
\hline Reduction (individual) & $-2 \pm 7$ & $1 \pm 8$ & $-14 \pm 34$ & $-2 \pm 25$ & $-1 \pm 19$ & $7 \pm 16$ & $-65 \pm 87$ & $44 \pm 37$ \\
\hline Pair 1 & $-2 \%$ & $-5 \%$ & $-40 \%$ & $-27 \%$ & $-19 \%$ & $-9 \%$ & $-167 \%$ & $-11 \%$ \\
\hline Pair 2 & $1 \%$ & $6 \%$ & $26 \%$ & $24 \%$ & $22 \%$ & $29 \%$ & $22 \%$ & $65 \%$ \\
\hline Pair 3 & $3 \%$ & $8 \%$ & $-45 \%$ & $-18 \%$ & $-13 \%$ & $10 \%$ & $-106 \%$ & $56 \%$ \\
\hline Pair 4 & $-12 \%$ & $-7 \%$ & $4 \%$ & $14 \%$ & $8 \%$ & $0 \%$ & $-10 \%$ & $64 \%$ \\
\hline
\end{tabular}

\begin{tabular}{|r|r|r|}
\hline \multicolumn{1}{|c|}{$\mathbf{H g}$} & $\boldsymbol{\alpha}-$ HBCD & $\mathbf{2 , 4 , 6}-$ TBP \\
\hline $\mathrm{mg} / \mathrm{kg}$ & $\mathrm{ng} / \mathrm{g}$ & $\mathrm{ng} / \mathrm{g}$ \\
\hline $0.020 \pm 0.004$ & $0.18 \pm 0.02$ & $0.22 \pm 0.14$ \\
\hline $0.021 \pm 0.002$ & $0.19 \pm 0.01$ & $0.22 \pm 0.09$ \\
\hline$-3 \%$ & $-7 \%$ & $4 \%$ \\
\hline$-5 \pm 13$ & $-9 \pm 17$ & $-18 \pm 69$ \\
\hline$-20 \%$ & $-12 \%$ & $14 \%$ \\
\hline $1 \%$ & $5 \%$ & $-122 \%$ \\
\hline$-12 \%$ & $4 \%$ & $21 \%$ \\
\hline $10 \%$ & $-31 \%$ & $14 \%$ \\
\hline
\end{tabular}

\begin{tabular}{|c|c|c|c|c|c|c|c|c|}
\hline Halibut & $\begin{array}{l}\text { dry } \\
\text { matter }\end{array}$ & lipid & $\mathrm{Fe}$ & $\mathrm{Cu}$ & Zn & As & Se & Cd \\
\hline Unit & $\%$ & $\%$ & $\mathrm{mg} / \mathrm{kg}$ & $\mathrm{mg} / \mathrm{kg}$ & $\mathrm{mg} / \mathrm{kg}$ & $\mathrm{mg} / \mathrm{kg}$ & $\mathrm{mg} / \mathrm{kg}$ & $\mathrm{mg} / \mathrm{kg}$ \\
\hline Raw (ng/g ww) & $30.4 \pm 1.5$ & $13.5 \pm 1.4$ & $0.6 \pm 0.4$ & $0.09 \pm 0.01$ & $3.0 \pm 0.3$ & $5 \pm 2$ & $0.29 \pm 0.08$ & $0.0008 \pm 0.0002$ \\
\hline Smoked (ng/g ww) & $35.9 \pm 2.1$ & $16.2 \pm 1.3$ & $0.6 \pm 0.1$ & $0.10 \pm 0.01$ & $3.2 \pm 0.3$ & $4 \pm 2$ & $0.29 \pm 0.10$ & $0.0008 \pm 0.0002$ \\
\hline Reduction (mean) & $-18 \%$ & $-20 \%$ & $-7 \%$ & $-7 \%$ & $-4 \%$ & $17 \%$ & $0.1 \%$ & $-2 \%$ \\
\hline Reduction (individual) & $-18 \pm 8$ & $-21 \pm 7$ & $-34 \pm 50$ & $-9 \pm 19$ & $-5 \pm 14$ & $14 \pm 17$ & $-3 \pm 36$ & $-4 \pm 22$ \\
\hline Pair 1 & $-23 \%$ & $-23 \%$ & $-100 \%$ & $-13 \%$ & $-22 \%$ & $13 \%$ & $5 \%$ & $-40 \%$ \\
\hline Pair 2 & $-10 \%$ & $-17 \%$ & $73 \%$ & $-40 \%$ & $-8 \%$ & $18 \%$ & $-53 \%$ & $-5 \%$ \\
\hline Pair 3 & $-8 \%$ & $-15 \%$ & $-10 \%$ & $7 \%$ & $18 \%$ & $23 \%$ & $13 \%$ & $26 \%$ \\
\hline Pair 4 & $-31 \%$ & $-32 \%$ & $-23 \%$ & $-18 \%$ & $-12 \%$ & $16 \%$ & $8 \%$ & $-9 \%$ \\
\hline Pair 5 & $-10 \%$ & $-20 \%$ & $-55 \%$ & $4 \%$ & $-3 \%$ & $11 \%$ & $37 \%$ & $-27 \%$ \\
\hline Pair 6 & $-22 \%$ & $-12 \%$ & $-89 \%$ & $-21 \%$ & $-31 \%$ & $-7 \%$ & $2 \%$ & $-13 \%$ \\
\hline Pair 7 & $-14 \%$ & $-16 \%$ & $-36 \%$ & $-5 \%$ & $0 \%$ & $9 \%$ & $-22 \%$ & $16 \%$ \\
\hline Pair 8 & $-27 \%$ & $-13 \%$ & $-42 \%$ & $-31 \%$ & $6 \%$ & $44 \%$ & $-15 \%$ & $-19 \%$ \\
\hline Pair 9 & $-22 \%$ & $-26 \%$ & $5 \%$ & $9 \%$ & $4 \%$ & $29 \%$ & $53 \%$ & $28 \%$ \\
\hline Pair 10 & $-14 \%$ & $-32 \%$ & $-62 \%$ & $18 \%$ & $-8 \%$ & $-15 \%$ & $-62 \%$ & $6 \%$ \\
\hline
\end{tabular}

\begin{tabular}{|r|r|r|}
\hline \multicolumn{1}{|c|}{$\mathbf{H g}$} & $\boldsymbol{\alpha}-\mathbf{H B C D}$ & $\mathbf{2 , 4 , 6}-\mathbf{T B P}$ \\
\hline $\mathrm{mg} / \mathrm{kg}$ & $\mathrm{ng} / \mathrm{g}$ & $\mathrm{ng} / \mathrm{g}$ \\
\hline $0.05 \pm 0.02$ & $0.06 \pm 0.02$ & $0.2 \pm 0.09$ \\
\hline $0.05 \pm 0.01$ & $0.05 \pm 0.02$ & $0.27 \pm 0.11$ \\
\hline $8 \%$ & $9 \%$ & $-31 \%$ \\
\hline $6 \pm 10$ & $7 \pm 24$ & $-34 \pm 31$ \\
\hline $0 \%$ & $20 \%$ & $-33 \%$ \\
\hline $7 \%$ & $18 \%$ & $-35 \%$ \\
\hline $23 \%$ & $-9 \%$ & $-87 \%$ \\
\hline $5 \%$ & $-31 \%$ & $-14 \%$ \\
\hline $3 \%$ & $-22 \%$ & $-19 \%$ \\
\hline$-9 \%$ & $20 \%$ & $-15 \%$ \\
\hline $6 \%$ & $32 \%$ & $-86 \%$ \\
\hline $16 \%$ & $42 \%$ & $-38 \%$ \\
\hline $16 \%$ & $-3 \%$ & $-27 \%$ \\
\hline$-3 \%$ & $5 \%$ & $11 \%$ \\
\hline
\end{tabular}

24 of 28 
Table S8. Reduction of PCB and PBDE congeners in Greenland halibut calculated as (raw-smoked)/raw. Raw (A) and smoked (B) fish levels (mean \pm sd, ng/g ww) and mean reduction compared to and individual reductions pairs (mean $\pm \mathrm{sd}$ ).

\begin{tabular}{|c|c|c|c|c|c|c|c|c|c|c|}
\hline Greenland halibut & PCB28 & PCB52 & PCB101 & PCB153 & PCB138 & PCB180 & PBDE47 & PBDE99 & PBDE154 & PBDE153 \\
\hline Unit & $\mathrm{ng} / \mathrm{g}$ & $\mathrm{ng} / \mathrm{g}$ & $\mathrm{ng} / \mathrm{g}$ & $\mathrm{ng} / \mathrm{g}$ & $\mathrm{ng} / \mathrm{g}$ & $\mathrm{ng} / \mathrm{g}$ & $\mathrm{ng} / \mathrm{g}$ & $\mathrm{ng} / \mathrm{g}$ & $\mathrm{ng} / \mathrm{g}$ & $\mathrm{ng} / \mathrm{g}$ \\
\hline $\operatorname{Raw}(\mathrm{A})$ & $0.64+/-0.1$ & $0.52+/-0.09$ & $0.63+/-0.1$ & $0.95+/-0.15$ & $0.59+/-0.08$ & $0.16+/-0.03$ & $0.17+/-0.04$ & $0.11+/-0.05$ & $0.01+/-0.005$ & $0.004+/-0.007$ \\
\hline Smoked (B) & $0.71+/-0.11$ & $0.64+/-0.13$ & $0.72+/-0.1$ & $1.14+/-0.17$ & $0.69+/-0.1$ & $0.17+/-0.03$ & $0.18+/-0.02$ & $0.1+/-0.02$ & $0.01+/-0.01$ & $0.01+/-0.01$ \\
\hline Reduction (mean) & $-10 \%$ & $-22 \%$ & $-14 \%$ & $-20 \%$ & $-17 \%$ & $-10 \%$ & $-5 \%$ & $10 \%$ & $-14 \%$ & $-158 \%$ \\
\hline Reduction (individual) & $-13+/-14$ & $-23+/-13$ & $-18+/-9$ & $-21+/-10$ & $-18+/-10$ & $-12+/-12$ & $-7+/-26$ & $-1+/-43$ & $-12+/-84$ & $-28+/-82$ \\
\hline Pair 1 & $-13 \%$ & $-33 \%$ & $-34 \%$ & $-41 \%$ & $-33 \%$ & $-35 \%$ & $-11 \%$ & $-7 \%$ & $15 \%$ & no data \\
\hline Pair 2 & $-1 \%$ & $-7 \%$ & $-10 \%$ & $-10 \%$ & $-3 \%$ & $-4 \%$ & $-6 \%$ & $-95 \%$ & $-126 \%$ & no data \\
\hline Pair 3 & $-5 \%$ & $-8 \%$ & $-11 \%$ & $-10 \%$ & $-8 \%$ & $-8 \%$ & $-11 \%$ & $17 \%$ & $27 \%$ & no data \\
\hline Pair 4 & $-18 \%$ & $-35 \%$ & $-18 \%$ & $-18 \%$ & $-17 \%$ & $-1 \%$ & $31 \%$ & $49 \%$ & $50 \%$ & $-3 \%$ \\
\hline Pair 5 & $-32 \%$ & $-34 \%$ & $-27 \%$ & $-25 \%$ & $-23 \%$ & $-10 \%$ & $-21 \%$ & $-4 \%$ & $-5 \%$ & $38 \%$ \\
\hline Pair 6 & $-18 \%$ & $-33 \%$ & $-17 \%$ & $-22 \%$ & $-23 \%$ & $-14 \%$ & $-51 \%$ & $12 \%$ & $-147 \%$ & $-120 \%$ \\
\hline Pair 7 & $-25 \%$ & $-30 \%$ & $-23 \%$ & $-25 \%$ & $-29 \%$ & $-28 \%$ & $-26 \%$ & $-33 \%$ & no data & no data \\
\hline Pair 8 & $14 \%$ & $-5 \%$ & $-15 \%$ & $-11 \%$ & $-10 \%$ & $-5 \%$ & $22 \%$ & $39 \%$ & $-13 \%$ & no data \\
\hline Pair 9 & no data & no data & no data & no data & no data & no data & no data & no data & no data & no data \\
\hline Pair 10 & $-22 \%$ & $-25 \%$ & $-8 \%$ & $-26 \%$ & $-19 \%$ & $-1 \%$ & $11 \%$ & $10 \%$ & $100 \%$ & no data \\
\hline
\end{tabular}




\subsection{Prawn dataset}

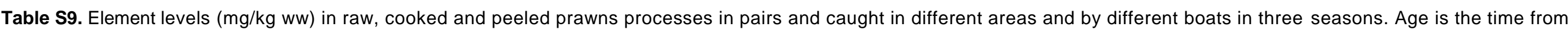
catching to cooking the raw prawn.

\begin{tabular}{|c|c|c|c|c|c|c|c|c|c|c|c|c|c|c|c|}
\hline processing & season & $\begin{array}{c}\text { pair } \\
\text { no. }\end{array}$ & $\begin{array}{l}\text { age } \\
\text { days }\end{array}$ & boat & Area & \multicolumn{10}{|c|}{ mg/kg wet weight } \\
\hline Raw & Spring & 1 & 6 & Lomur & KG016 & 0.02 & 7.8 & 2.8 & 6.4 & $2.5^{\star}$ & 0.16 & 0.149 & 0.008 & 0.000 & 0.012 \\
\hline Raw & Spring & 2 & 4 & Lomur & KR017 & 0.01 & 10.3 & 4.2 & 8.4 & $2.5^{\star}$ & 0.21 & 0.216 & 0.007 & 0.001 & 0.020 \\
\hline Raw & Spring & 3 & 5 & Angun-nguaq II & KT017 & 0.11 & 17.4 & 5.9 & 10.5 & 18.1 & 0.28 & 0.319 & 0.016 & 0.003 & 0.023 \\
\hline Raw & Summer & 4 & 5 & Angun-nguaq II & LE $23+$ LH 25 & 0.05 & 10.0 & 4.2 & 11.0 & 13.4 & 0.27 & 0.321 & 0.011 & 0.013 & 0.011 \\
\hline Raw & Summer & 5 & 4 & Angun-nguaq II & LH $25+$ LH 24 & 0.14 & 31.0 & 6.3 & 11.8 & 18.7 & 0.36 & 0.541 & 0.015 & 0.010 & 0.018 \\
\hline Raw & Summer & 6 & 5 & Daavi & LK $25+$ LL 25 & 0.17 & 26.0 & 5.7 & 12.1 & 11.2 & 0.33 & 0.639 & 0.016 & 0.004 & 0.019 \\
\hline Raw & Autumn & 7 & 4 & Lomur & LS 14 & 0.31 & 40.5 & 6.5 & 13.6 & 17.3 & 0.44 & 0.664 & 0.026 & 0.005 & 0.012 \\
\hline Raw & Autumn & 8 & 5 & Bingo 3 & LJ 27 & 0.27 & 39.6 & 5.8 & 11.1 & 14.4 & 0.34 & 0.478 & 0.015 & 0.014 & 0.024 \\
\hline Raw & Autumn & 9 & 5 & Lomur & LT 15 & 0.15 & 18.3 & 5.2 & 12.0 & 17.3 & 0.37 & 0.481 & 0.026 & 0.000 & 0.012 \\
\hline Cooked & Spring & 1 & 6 & Lomur & KG016 & 0.00 & 7.4 & 2.0 & 6.4 & 3.1 & 0.13 & 0.111 & 0.008 & 0.001 & 0.015 \\
\hline Cooked & Spring & 2 & 4 & Lomur & KR017 & 0.05 & 11.2 & 3.5 & 8.1 & 2.7 & 0.17 & 0.171 & 0.008 & 0.003 & 0.018 \\
\hline Cooked & Spring & 3 & 5 & Angun-nguaq II & KT017 & 0.08 & 21.8 & 4.7 & 10.2 & 15.5 & 0.24 & 0.223 & 0.015 & 0.024 & 0.019 \\
\hline Cooked & Summer & 4 & 5 & Angun-nguaq II & LE $23+\mathrm{LH} 25$ & 0.04 & 8.8 & 3.8 & 11.4 & 13.1 & 0.27 & 0.261 & 0.011 & 0.008 & 0.009 \\
\hline Cooked & Summer & 5 & 4 & Angun-nguaq II & $\mathrm{LH} 25+\mathrm{LH} 24$ & 0.12 & 24.0 & 4.6 & 10.5 & 16.4 & 0.29 & 0.322 & 0.011 & 0.004 & 0.016 \\
\hline Cooked & Summer & 6 & 5 & Daavi & LK 25 + LL 25 & 0.12 & 16.9 & 5.6 & 10.4 & 11.4 & 0.28 & 0.459 & 0.011 & 0.001 & 0.014 \\
\hline Cooked & Autumn & 7 & 4 & Lomur & LS 14 & 0.17 & 25.5 & 4.1 & 12.0 & 13.3 & 0.30 & 0.358 & 0.018 & 0.007 & 0.009 \\
\hline Cooked & Autumn & 8 & 5 & Bingo 3 & LJ 27 & 0.28 & 27.8 & 3.0 & 9.3 & 9.0 & 0.24 & 0.176 & 0.010 & 0.015 & 0.013 \\
\hline Cooked & Autumn & 9 & 5 & Lomur & LT 15 & 0.30 & 33.8 & 3.8 & 11.1 & 14.6 & 0.32 & 0.328 & 0.021 & 0.009 & 0.008 \\
\hline Peeled & Spring & 1 & 6 & Lomur & KG016 & 0.00 & 0.6 & 1.4 & 7.9 & 2.7 & 0.15 & 0.007 & 0.013 & 0.000 & 0.011 \\
\hline Peeled & Spring & 2 & 4 & Lomur & KR017 & 0.00 & 0.9 & 1.5 & 8.7 & 2.2 & 0.18 & 0.006 & 0.013 & 0.000 & 0.012 \\
\hline Peeled & Spring & 3 & 5 & Angun-nguaq II & KT017 & 0.00 & 0.9 & 1.5 & 9.3 & 14.6 & 0.20 & 0.006 & 0.022 & 0.000 & 0.020 \\
\hline Peeled & Summer & 4 & 5 & Angun-nguaq II & LE $23+$ LH 25 & 0.00 & 1.1 & 1.4 & 8.9 & 13.0 & 0.19 & 0.009 & 0.018 & 0.000 & 0.021 \\
\hline Peeled & Summer & 5 & 4 & Angun-nguaq II & $\mathrm{LH} 25+\mathrm{LH} 24$ & 0.00 & 1.4 & 1.6 & 9.0 & 13.9 & 0.20 & 0.010 & 0.017 & 0.000 & 0.015 \\
\hline Peeled & Summer & 6 & 5 & Daavi & LK 25 + LL 25 & 0.04 & 1.3 & 1.4 & 8.7 & 7.3 & 0.18 & 0.013 & 0.018 & 0.000 & 0.008 \\
\hline Peeled & Autumn & 7 & 4 & Lomur & LS 14 & 0.05 & 1.9 & 1.4 & 8.9 & 14.0 & 0.20 & 0.011 & 0.033 & 0.000 & 0.003 \\
\hline Peeled & Autumn & 8 & 5 & Bingo 3 & LJ 27 & 0.06 & 1.3 & 1.3 & 8.3 & 11.0 & 0.20 & 0.009 & 0.019 & 0.000 & 0.007 \\
\hline Peeled & Autumn & 9 & 5 & Lomur & LT 15 & 0.07 & 1.1 & 1.2 & 7.7 & 12.0 & 0.21 & 0.009 & 0.029 & 0.000 & 0.003 \\
\hline
\end{tabular}

* Two spring catches have much lower As than content all other. 


\subsection{Prawn reductions}

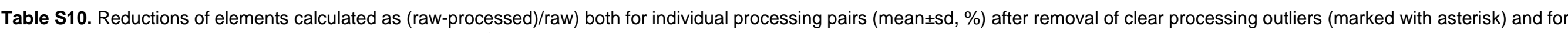
element levels in raw and processed prawns (mean $\pm s d, \mathrm{mg} / \mathrm{kg} \mathrm{ww}$ ).

\begin{tabular}{|c|c|c|c|c|c|c|c|c|c|}
\hline & $\mathrm{Cr}$ & $\mathrm{Fe}$ & $\mathrm{Cu}$ & Zn & As & $\mathrm{Se}$ & Cd & $\mathrm{Hg}$ & iAs \\
\hline Unit & $\mathrm{mg} / \mathrm{kg}$ & $\mathrm{mg} / \mathrm{kg}$ & $\mathrm{mg} / \mathrm{kg}$ & $\mathrm{mg} / \mathrm{kg}$ & $\mathrm{mg} / \mathrm{kg}$ & $\mathrm{mg} / \mathrm{kg}$ & $\mathrm{mg} / \mathrm{kg}$ & $\mathrm{mg} / \mathrm{kg}$ & $\mathrm{mg} / \mathrm{kg}$ \\
\hline Raw level & $0.15 \pm 0.11$ & $23 \pm 13$ & $5 \pm 1$ & $11 \pm 2$ & $13 \pm 6$ & $0.31 \pm 0.09$ & $0.4 \pm 0.2$ & $0.016 \pm 0.007$ & $0.017 \pm 0.005$ \\
\hline Cooked level & $0.13 \pm 0.10$ & $20 \pm 9$ & $4 \pm 1$ & $10 \pm 2$ & $11 \pm 5$ & $0.25 \pm 0.06$ & $0.3 \pm 0.1$ & $0.013 \pm 0.004$ & $0.013 \pm 0.004$ \\
\hline Peeled level & $0.03 \pm 0.03$ & $1.2 \pm 0.4$ & $1.4 \pm 0.1$ & $8.6 \pm 0.5$ & $10 \pm 5$ & $0.19 \pm 0.02$ & $0.009 \pm 0.002$ & $0.020 \pm 0.007$ & $0.011 \pm 0.007$ \\
\hline Reduction, cooked (mean) & $7 \%$ & $12 \%$ & $25 \%$ & $8 \%$ & $14 \%$ & $19 \%$ & $37 \%$ & $19 \%$ & $19 \%$ \\
\hline Reduction, cooked (individuel) & $23 \pm 16$ & $14 \pm 22$ & $25 \pm 14$ & $7 \pm 7$ & $8 \pm 18$ & $18 \pm 9$ & $34 \pm 14$ & $15 \pm 17$ & $23 \pm 13$ \\
\hline Cooked 1 & $79 \%$ & $6 \%$ & $30 \%$ & $-1 \%$ & $-25 \%$ & $17 \%$ & $26 \%$ & $-11 \%$ & $-28 \%$ * \\
\hline Cooked 2 & $-370 \%{ }^{*}$ & $-9 \%$ & $18 \%$ & $3 \%$ & $-9 \%$ & $20 \%$ & $21 \%$ & $-3 \%$ & $11 \%$ \\
\hline Cooked 3 & $30 \%$ & $-25 \%$ & $20 \%$ & $2 \%$ & $15 \%$ & $14 \%$ & $30 \%$ & $8 \%$ & $16 \%$ \\
\hline Cooked 4 & $19 \%$ & $12 \%$ & $11 \%$ & $-3 \%$ & $2 \%$ & $2 \%$ & $19 \%$ & $-3 \%$ & $17 \%$ \\
\hline Cooked 5 & $14 \%$ & $23 \%$ & $28 \%$ & $11 \%$ & $13 \%$ & $19 \%$ & $40 \%$ & $27 \%$ & $7 \%$ \\
\hline Cooked 6 & $28 \%$ & $35 \%$ & $2 \%$ & $14 \%$ & $-1 \%$ & $13 \%$ & $28 \%$ & $32 \%$ & $29 \%$ \\
\hline Cooked 7 & $47 \%$ & $37 \%$ & $37 \%$ & $12 \%$ & $23 \%$ & $32 \%$ & $46 \%$ & $31 \%$ & $25 \%$ \\
\hline Cooked 8 & $-2 \%$ & $30 \%$ & $48 \%$ & $16 \%$ & $38 \%$ & $30 \%$ & $63 \%$ & $33 \%$ & $44 \%$ \\
\hline Cooked 9 & $-103 \% *$ & $-85 \% *$ & $28 \%$ & $8 \%$ & $15 \%$ & $14 \%$ & $32 \%$ & $19 \%$ & $35 \%$ \\
\hline Reduction, peeled (mean) & $82 \%$ & $95 \%$ & $73 \%$ & $20 \%$ & $21 \%$ & $38 \%$ & $98 \%$ & $-30 \%$ & $34 \%$ \\
\hline Reduction, peeled & $87 \pm 16$ & $94 \pm 2$ & $71 \pm 9$ & $17 \pm 19$ & $18 \pm 14$ & $34 \pm 15$ & $98 \pm 1$ & $-37 \pm 26$ & $44 \pm 30$ \\
\hline Peeled 1 & $100 \%$ & $92 \%$ & $52 \%$ & $-23 \%$ & $-10 \%$ & $7 \%$ & $96 \%$ & $-76 \%$ & $10 \%$ \\
\hline Peeled 2 & $100 \%$ & $91 \%$ & $64 \%$ & $-4 \%$ & $14 \%$ & $14 \%$ & $97 \%$ & $-73 \%$ & $39 \%$ \\
\hline Peeled 3 & $100 \%$ & $95 \%$ & $74 \%$ & $11 \%$ & $19 \%$ & $29 \%$ & $98 \%$ & $-34 \%$ & $11 \%$ \\
\hline Peeled 4 & $95 \%$ & $89 \%$ & $66 \%$ & $20 \%$ & $3 \%$ & $30 \%$ & $97 \%$ & $-60 \%$ & $-83 \%{ }^{*}$ \\
\hline Peeled 5 & $100 \%$ & $96 \%$ & $75 \%$ & $23 \%$ & $26 \%$ & $43 \%$ & $98 \%$ & $-16 \%$ & $14 \%$ \\
\hline Peeled 6 & $76 \%$ & $95 \%$ & $76 \%$ & $28 \%$ & $35 \%$ & $46 \%$ & $98 \%$ & $-7 \%$ & $59 \%$ \\
\hline Peeled 7 & $83 \%$ & $95 \%$ & $79 \%$ & $35 \%$ & $19 \%$ & $54 \%$ & $98 \%$ & $-28 \%$ & $77 \%$ \\
\hline Peeled 8 & $77 \%$ & $97 \%$ & $78 \%$ & $25 \%$ & $24 \%$ & $41 \%$ & $98 \%$ & $-31 \%$ & $71 \%$ \\
\hline Peeled 9 & $56 \%$ & $94 \%$ & $77 \%$ & $36 \%$ & $30 \%$ & $44 \%$ & $98 \%$ & $-12 \%$ & $75 \%$ \\
\hline
\end{tabular}


2.1 Prawn plot of replicates

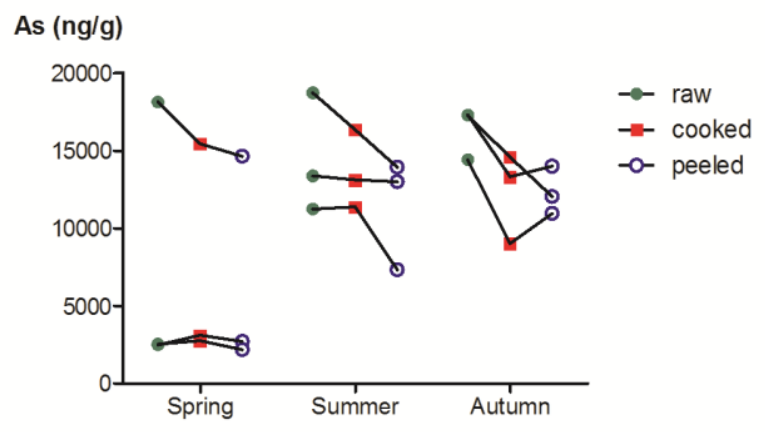

iAs (ng/g)

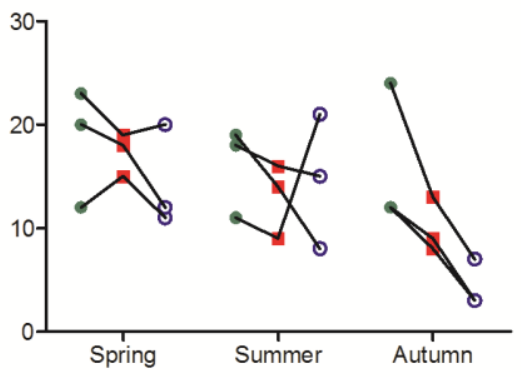

$\mathrm{Cr}(\mathrm{ng} / \mathrm{g})$
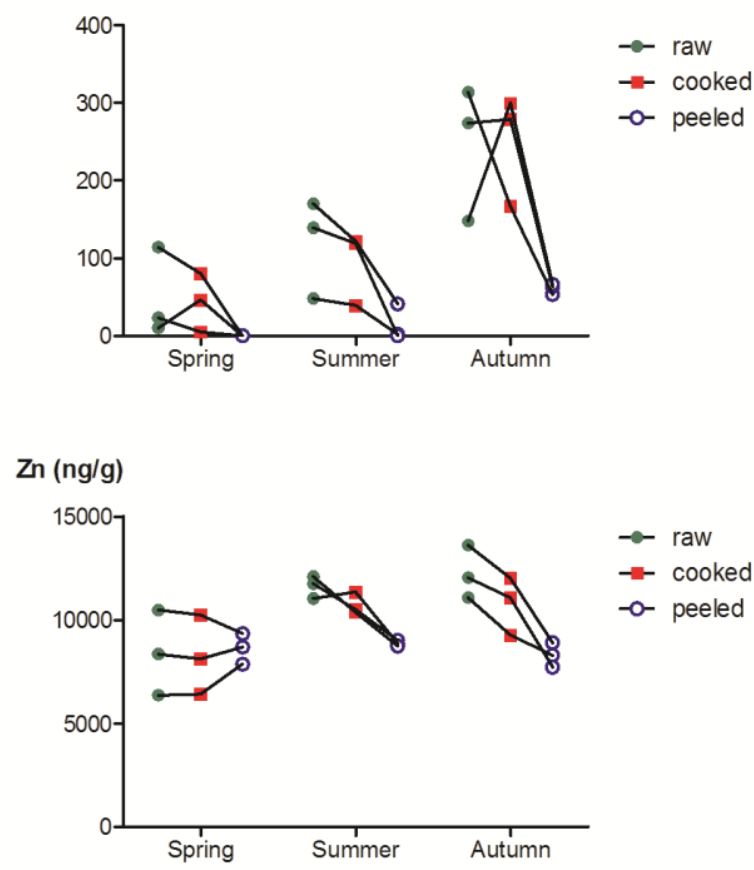

$\mathrm{Hg}(\mathrm{ng} / \mathrm{g})$

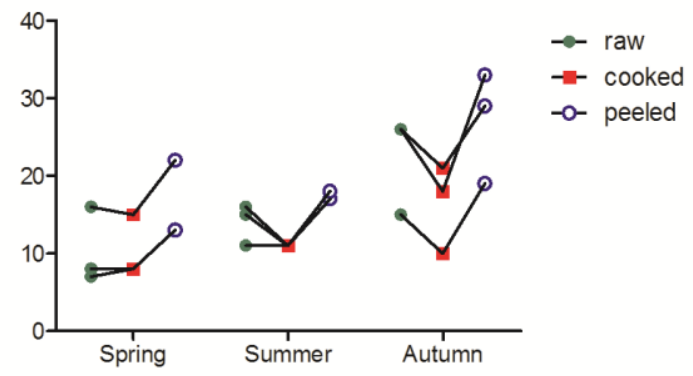

Cd (ng/g)
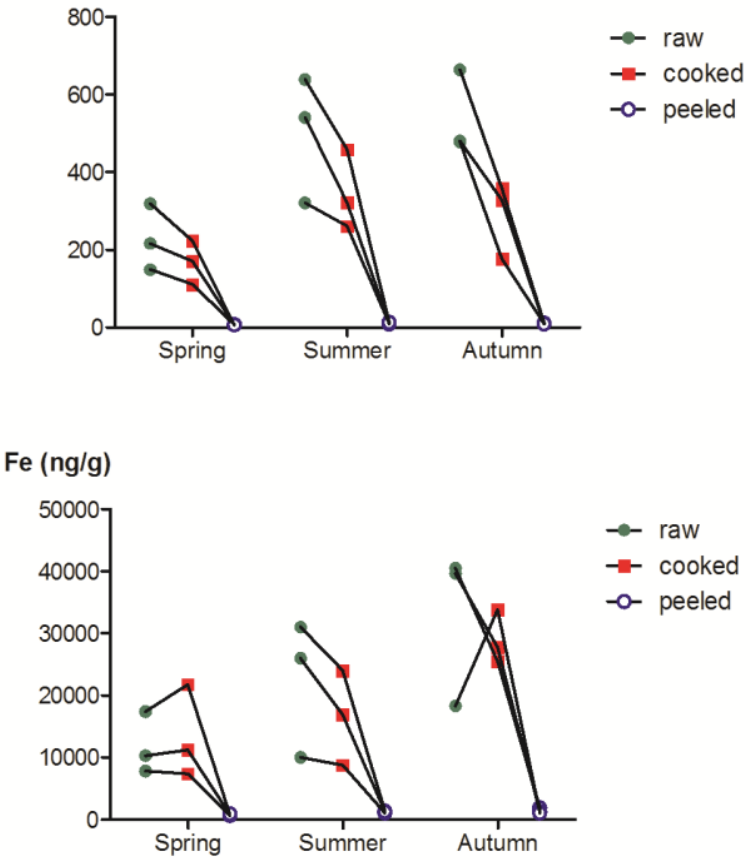

Se $(\mathrm{ng} / \mathrm{g})$
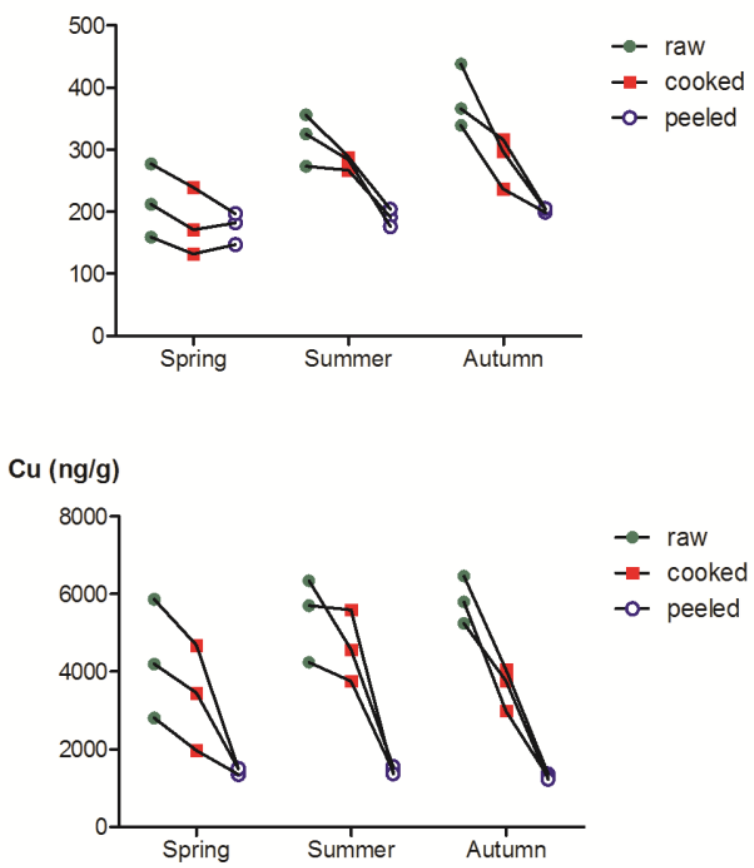

$\mathrm{Pb}(\mathrm{ng} / \mathrm{g})$

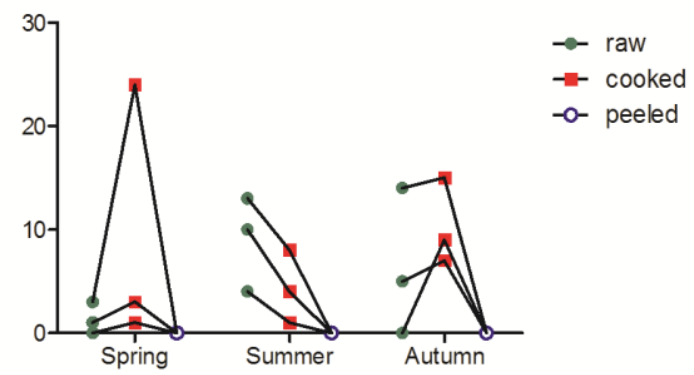

'Figure S3. All total elements and inorganic arsenic (iAs) levels in industrial processed prawns caught in different seasons. Samples processed as pairs are connected with a blue line. Replicates $(n=3)$ of spring prawns level were much different with high As in the catching areas KT017 and low As in KG016 and KR017 (for exact location see Figure S1). 